\title{
Differences and implications in biogeochemistry from maximizing entropy production locally versus globally
}

\author{
J. J. Vallino \\ Marine Biological Laboratory, Woods Hole, Massachusetts, USA \\ Received: 31 December 2010 - Published in Earth Syst. Dynam. Discuss.: 19 January 2011 \\ Revised: 25 May 2011 - Accepted: 27 May 2011 - Published: 17 June 2011
}

\begin{abstract}
In this manuscript we investigate the use of the maximum entropy production (MEP) principle for modeling biogeochemical processes that are catalyzed by living systems. Because of novelties introduced by the MEP approach, many questions need to be answered and techniques developed in the application of MEP to describe biological systems that are responsible for energy and mass transformations on a planetary scale. In previous work we introduce the importance of integrating entropy production over time to distinguish abiotic from biotic processes under transient conditions. Here we investigate the ramifications of modeling biological systems involving one or more spatial dimensions. When modeling systems over space, entropy production can be maximized either locally at each point in space asynchronously or globally over the system domain synchronously. We use a simple two-box model inspired by two-layer ocean models to illustrate the differences in local versus global entropy maximization. Synthesis and oxidation of biological structure is modeled using two autocatalytic reactions that account for changes in community kinetics using a single parameter each. Our results show that entropy production can be increased if maximized over the system domain rather than locally, which has important implications regarding how biological systems organize and supports the hypothesis for multiple levels of selection and cooperation in biology for the dissipation of free energy.
\end{abstract}

\section{Introduction}

There is a long history of research that attempts to understand and model ecosystems from a goal-based perspective dating back to at least Lotka (1922), who argued that ecosystems

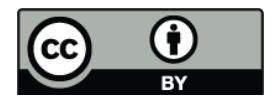

Correspondence to: J. J. Vallino

(jvallino@mbl.edu) organize to maximize power. Many of the proposed theories (e.g., Morowitz, 1968; Schrödinger, 1944; Odum and Pinkerton, 1955; Margalef, 1968; Prigogine and Nicolis, 1971; Schneider and Kay, 1994; Bejan, 2007; Jorgensen et al., 2000; Toussaint and Schneider, 1998; Weber et al., 1988; Ulanowicz and Platt, 1985) are inspired by or derived from thermodynamics, because ecosystems are comprised by numerous agents, and there is the desire to understand their collective action, which is an inherently thermodynamic-like approach. Being that ecosystems are open, energetic systems, thermodynamics is particularly relevant for understanding biogeochemistry, which is largely under microbial control, or more aptly, molecular machines (Falkowski et al., 2008), that span the realm between pure chemistry and biology. While significant effort and progress has been made in understanding organismal metabolism in an ecosystem context (West et al., 1997), it is rather surprising that we still lack an agreed upon theory that can explain and quantitatively predict ecosystem biogeochemistry that is independent of the constituent organisms. Perhaps a single theory does not exist, and ecosystem biogeochemistry depends completely or substantially on the nuances of the constituent organisms that comprise an ecosystem. However, at the appropriate scale and perspective it appears likely that systems organize in a predictable manner independent of species composition, as the planet's biogeochemical processes have remained relative stable over hundreds of millions of years but the organisms that comprise ecosystems have changed significantly over this period.

Consider primary producers in terrestrial versus marine ecosystems. While there is a definitive morphological discontinuity between marine systems that are composed of planktonic algae and terrestrial ecosystems comprised of trees, shrubs or grasses, the distinction and discontinuity is removed when considering solar energy acquisition and carbon dioxide fixation, which both do similarly. Because of the large degrees of freedom, it is likely impossible to predict

Published by Copernicus Publications on behalf of the European Geosciences Union. 
the nature of the organisms that evolve to facilitate energy and mass transformations in one ecosystem versus the next or how their populations vary over time, but at the level of free energy dissipation via biogeochemistry, the problem may be more tractable. The problem is similar to predicting weather versus climate, where the latter can be predicted over long time scales at the expense of details necessary for weather prediction whose accuracy decays rapidly with time. Our objective is to understand biogeochemistry at the level of generic biological structure catalyzing chemical reactions. Understanding energy and mass flow catalyzed by living systems is particularly relevant for understanding how the biosphere will respond to global change, and predicting biogeochemical responses is essential before any geoengineering projects could be responsibly implemented.

Many of the thermodynamically inspired ecosystem theories are more similar than different (Fath et al., 2001; Jorgensen, 1994), but the theory of maximum entropy production (MEP) has made great progress in understanding how biotic and abiotic systems may organize under nonequilibrium steady state conditions when sufficient degrees of freedom exist. It appears Paltridge (1975) was the first to apply MEP as an objective function for modeling global heat transport, but it was not until the theoretical support provided by Dewar (2003) that research in MEP theory and applications garnered greater interest, particularly in Earth systems science (Lorenz et al., 2001; Kleidon et al., 2003; Kleidon and Lorenz, 2005a, b; Dyke and Kleidon, 2010). While Dewar's initial work has received some criticisms, there have been several other approaches that arrive at the same nonequilibrium steady state result of MEP (see Niven, 2009 and references therein). The MEP principle states that systems will organize to maximize the rate of entropy production, which is an appealing extension to the second law of thermodynamics for nonequilibrium systems. In essence, nonequilibrium systems will attempt to approach equilibrium via the fastest possible pathway, which can include the organization of complex structures if they facilitate entropy production. However, none of the current MEP theories incorporate information content of the system, such as that contained within an organism's genome, even though several of the MEP analyses are derived from Jaynes (2003) maximum entropy (MaxEnt) formulation that is information based. Furthermore, current MEP theory suggests that maximizing entropy production locally will maximize entropy production over the system domain, at least for flow-controlled systems (Niven, 2009). Because an MEP-based model can be implemented with either local or global optimization, this manuscript investigates if the type of spatial optimization affects the solution to a simple, MEP-based biogeochemistry model.

In this manuscript we will assume that biological systems organize to maximize entropy production, which is synonymous with maximizing the dissipation rate of Gibbs free energy for systems under constant temperature and pressure. Living organisms are viewed here as mere catalysts facilitat- ing autocatalytic reactions for the dissipation of free energy. We will also continue our main hypothesis (Vallino, 2010), that the acquisition of Shannon information (Shannon, 1948), or more precisely useful information (Adami, 2002; Adami et al., 2000), via evolution facilitates the production of entropy when averaged over time. It is the ability of living systems to store information that allows them to out-compete abiotic systems in entropy production under appropriate conditions. Here, we will examine how information may also facilitate entropy production averaged over space. For our system, we will consider a simple two-box model where entropy production in each box is largely governed by two reactions that determined the rate of biological structure (i.e., catalyst) synthesis and degradation.

\section{Model system}

To examine how internal entropy production depends on either local or global entropy production optimization, we use a simple two-box model reminiscent of ocean biogeochemistry models developed to capture processes in the photic and aphotic zones of oceans (Fig. 1) (Ianson and Allen, 2002). As customary in oceanography, we model a water column where all boxes and boundaries have unit surface area, so that extensive variables only depend on box depth, $h$, and will be calculated on a per $\mathrm{m}^{2}$ basis. Model focus is placed on dissipation of free energy by synthesis and destruction of biological structures $\left(\dot{\xi}_{1}\right.$ and $\left.\dot{\xi}_{2}\right)$ from and to chemical constituents $\left(\mathrm{CH}_{2} \mathrm{O}, \mathrm{NH}_{3}, \mathrm{O}_{2}\right.$ and $\left.\mathrm{H}_{2} \mathrm{CO}_{3}\right)$ within the two layers, but entropy of mixing between boxes and boundaries is accounted for. The photic zone is typically energy replete but resource limited, while the aphotic zone is its complement: energy limited but resource replete. Our model captures these two differing states; however, we replace energy input via photosynthetic active radiation with energy input via the diffusion of chemical potential from a fixed upper boundary condition into the surface layer box. Nitrogen in the form of ammonia is allowed to diffuse into the bottom box [2] from sediments, which fixes the lower boundary condition [3]. Hence, energy flows into the system via box [1] and resources (nitrogen) flow in via box [2]. All constituents are allowed to freely diffuse between boxes [1] and [2], but only $\mathrm{CH}_{2} \mathrm{O}, \mathrm{O}_{2}$ and $\mathrm{H}_{2} \mathrm{CO}_{3}$ are permitted across the upper boundary, while only $\mathrm{NH}_{3}$ can diffuse across the lower boundary (Fig. 1).

In our simplified model system, we consider only two autocatalytic chemical reactions occur within each box, as constrained by the following stoichiometric equations,

$$
\begin{aligned}
& \mathrm{CH}_{2} \mathrm{O}+\left(1-\varepsilon_{1}\right) \mathrm{O}_{2}+\varepsilon_{1} \rho \mathrm{NH}_{3} \stackrel{\mathscr{S}_{1}}{\longrightarrow} \varepsilon_{1} \mathscr{S}_{1}+\left(1-\varepsilon_{1}\right) \mathrm{H}_{2} \mathrm{CO}_{3} \\
& \left(\delta_{1} \mathscr{S}_{1}+\delta_{2} \mathscr{S}_{2}\right)+\left(1-\varepsilon_{2}\right) \mathrm{O}_{2} \stackrel{\mathscr{g}_{2}}{\longrightarrow} \varepsilon_{2} \dot{S}_{2}+\left(1-\varepsilon_{2}\right)\left(\mathrm{H}_{2} \mathrm{CO}_{3}+\rho \mathrm{NH}_{3}\right)
\end{aligned}
$$

where the stoichiometry of biological structure, $\dot{\mathscr{S}}_{i}$, is $\mathrm{CH}_{2} \mathrm{O}\left(\mathrm{NH}_{3}\right)_{\rho}, \rho$ is the $\mathrm{N}: \mathrm{C}$ ratio of biological structure and 


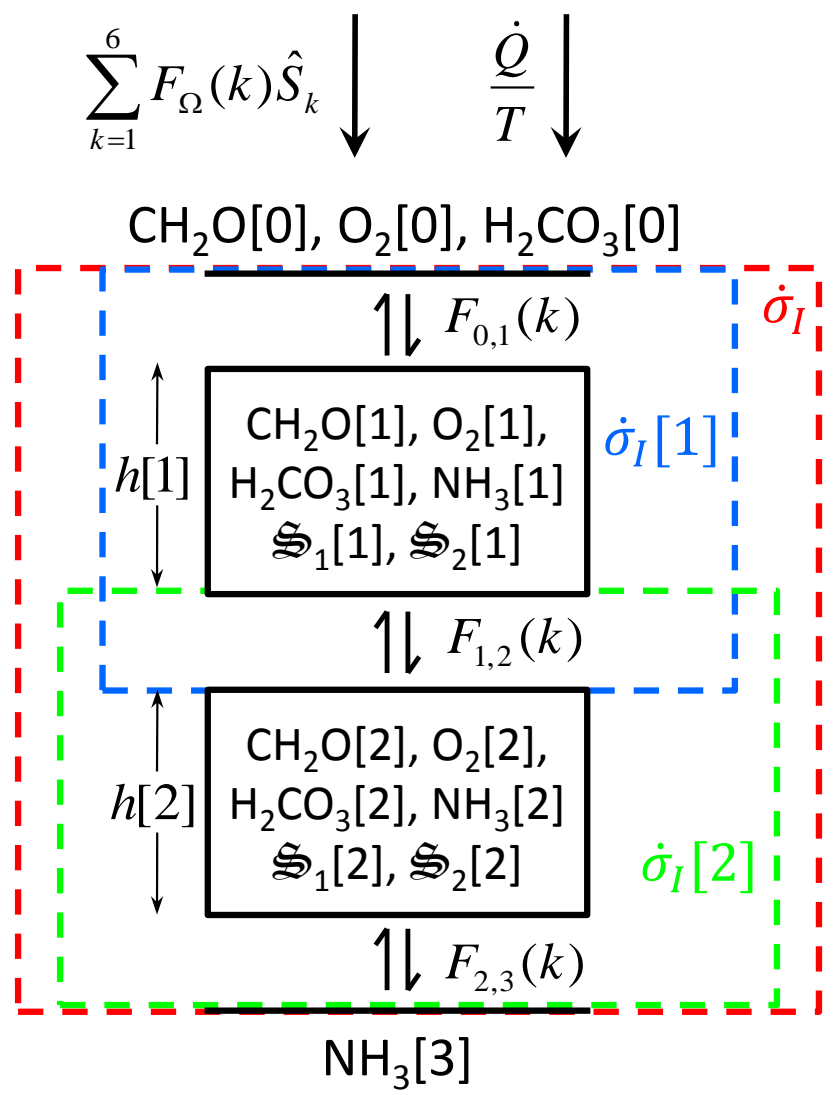

Fig. 1. Schematic of the two box model representing a water column with unit cross sectional area with associated state variables and boundary conditions. All fluxes between boxes and boundaries are governed by diffustion (see Eq. (12)) and only $\mathrm{CH}_{2} \mathrm{O}, \mathrm{O}_{2}$ and $\mathrm{H}_{2} \mathrm{CO}_{3}$ are exchanged accross boundary [0] and box [1]. Similarly, only $\mathrm{NH}_{3}$ is allowed across box [2] and boundary [3]. Boundary concentrations are held at fix values throughout the simulation and represent the external environmental conditions (see Table 2). Internal entropy production for the whole system, $\dot{\sigma}_{I}$, upper box, $\dot{\sigma}_{I}[1]$, and lower box, $\dot{\sigma}_{I}[2]$, are conducted around the red, blue and green dashed boundary boxes, resepctively.

$\varepsilon_{i}$ is the growth efficiency for biological structure synthesis from either $\mathrm{CH}_{2} \mathrm{O}$ or $\mathcal{B}_{i}$ and represents moles of $\mathcal{B}_{i}$ produced per mole of substrate consumed, so it is dimensionless. Note, as growth efficiency approaches zero, both reactions represent the complete oxidation of reduced carbon to $\mathrm{CO}_{2}$ and $\mathrm{H}_{2} \mathrm{O}$. In reaction (1), biological structure, ${ }_{1}$, catalyzes its own synthesis from sugar (unit carbon basis) and available ammonia thereby fulfilling the primary producer role. Reaction (2) represents heterotrophic organisms that consume biological structure synthesized from reaction (1), $\mathcal{S}_{1}$, but also functions in a cannibalistic mode by consuming $\mathscr{Z}_{2}$ as well. While cannibalism could be replaced by inclusion of a sufficient number of higher trophic levels for closure, this would lead to greater degrees of model freedom that are not important for this study, but would be more typical of natural ecosystems (Edwards and Yool, 2000). To minimize parameterization, we assume that biological structure is degraded indiscriminately by $\mathcal{S}_{2}$, so that the stoichiometric coefficients, $\delta_{i}$, in reaction (2) are given by (mole compound (mole reaction extent) ${ }^{-1}$ ),

$\delta_{i}=\frac{C_{\mathscr{S}_{i}}}{C_{\mathscr{S}_{1}}+C_{\mathscr{S}_{2}}}=\frac{C_{\mathscr{S}_{i}}}{C_{\mathscr{S}_{T}}}, \quad$ for $i=1,2$,

where $C_{\mathcal{B}_{i}}$ is the concentration $\left(\mathrm{mmol} \mathrm{m}^{-3}\right)$ of biological structure $i$.

Typically, Holling-type kinetics (Holling, 1965) are used to describe reaction rates for reactions (1) and (2) based on a limiting substrate or substrates. However, kinetic parameters (e.g., $\left.\mu^{\text {max }}, \mathrm{K}_{\mathrm{M}}\right)$ in Holling-type expressions depend on community composition, so Holling kinetic equations need to be reparameterized as community composition changes. Since an underlying hypothesis of the MEP principle when applied to living systems is that they will evolve and organize to achieve an MEP state (Vallino, 2010), we cannot a prior set parameters in a kinetic model as we do not know the nature of the community composition nor the corresponding kinetic parameter values that will lead to an MEP state. Kinetic parameters need to be dynamic to reflect community composition changes. To achieve this objective, we have developed a novel kinetic expression that can capture reaction kinetics in a manner consistent with community compositional changes. The form of our kinetic expression takes the familiar hyperbolic shape of the Monod equation (Monod, 1949), where substrate specific up-take rate is given by $\left(\mathrm{d}^{-1}\right)$,

$v_{i}=v^{*} \varepsilon_{i}^{2}\left(1-\varepsilon_{i}^{2}\right) \prod_{j=1}\left(\frac{C_{j}}{C_{j}+\kappa^{*} \varepsilon_{i}^{4}}\right)$

and specific growth rate readily follows from Eq. (4) as $\left(d^{-1}\right)$,

$\mu_{i}=\varepsilon_{i} v_{i}$

In Eqs. (4) and (5), $v^{*} \varepsilon_{i}^{2}\left(1-\varepsilon_{i}^{2}\right)$ is the maximum specific uptake rate of substrate, $\varepsilon_{i} \nu^{*} \varepsilon_{i}^{2}\left(1-\varepsilon_{i}^{2}\right)$ is equivalent to the maximum specific growth rate term in the Monod equation, $C_{j}$ is the concentration $\left(\mathrm{mmol} \mathrm{m}^{-3}\right)$ of one or more growth limiting substrates, such as $\mathrm{NH}_{3}, \varepsilon_{i}$ is the growth efficiency (dimensionless) as used in reactions (1) and (2), and $v^{*}\left(\mathrm{~d}^{-1}\right)$ and $\kappa^{*}\left(\mathrm{mmol} \mathrm{m}^{-3}\right)$ are universal parameters that remain fixed regardless of community composition. Equation (5) differs from the Monod equation in several important ways. The effective Monod "constant", $\mathrm{K}_{\mathrm{M}}$, is represented by $\kappa^{*} \varepsilon_{i}^{4}$, so depends on growth efficiency. The rational for this dependency is that nutrients at low concentration require free energy expenditure to transport them into the cell against a concentration gradient; consequently, organisms that have evolved to grow under low nutrients conditions (i.e., K-selected, Pianka, 1970) will, by thermodynamic necessity, grow at lower efficiencies. The $\left(1-\varepsilon_{i}^{2}\right)$ 


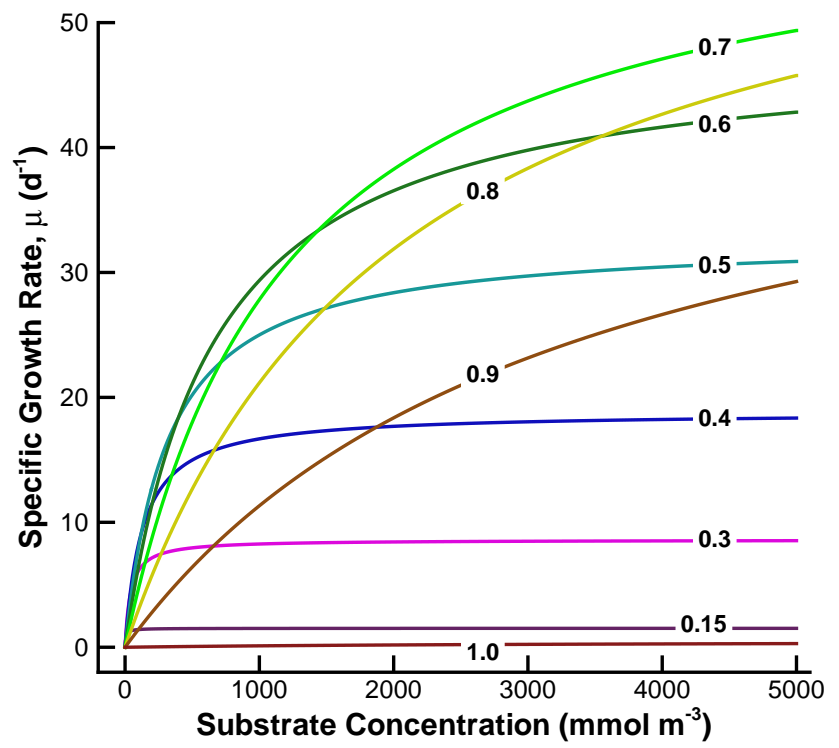

Fig. 2. Specific growth rate as a function of substrate concentrations based on Eqs. (4) and (5) for different values for $\varepsilon(0.15,0.3,0.4$, $0.5,0.6,0.7,0.8,0.8,1$.) using the universal kinetic parameters values of $350 \mathrm{~d}^{-1}$ and $5000 \mathrm{mmol} \mathrm{m}^{-3}$ for $\nu^{*}$ and $\kappa^{*}$, respectively.

term in Eq. (4) approximately accounts for thermodynamic constraints on kinetics, because net reaction rate must approach zero as reaction free energy tends toward zero (Jin and Bethke, 2003; Boudart, 1976), which is equivalent to a growth efficiency of 1 . The leading $\varepsilon_{i}^{2}$ term in Eq. (4) is empirically motivated to account for reduced substrate uptake rates at low growth efficiency.

The universal parameters, $v^{*}$ and $\kappa^{*}$, have been chosen to qualitatively match observations of bacterial growth. Under oligotrophic conditions often found in ocean gyres', bacterial specific growth rate is typically $1-2 \mathrm{~d}^{-1}$, with growth efficiencies of 10-20\%, and substrate concentrations in the $\mu \mathrm{M}$ or lower range (Del Giorgio and Cole, 1998; Carlson et al., 1999). At the other extreme, bacteria grown under ideal laboratory conditions show specific growth rates as fast as $50 \mathrm{~d}^{-1}$, with growth efficiencies around 50-60\%, provided substrate concentrations are in the mM range (Bailey, 1977; Lendenmann and Egli, 1998). Equations (4) and (5) capture these approximate trophic extremes with values of $\kappa^{*}$ of $5000 \mathrm{mmol} \mathrm{m}^{-3}$ and $v^{*}$ of $350 \mathrm{~d}^{-1}$ (Fig. 2). The usefulness of the kinetic expressions (Eqs. 4 and 5) is their ability to generate organismal growth kinetics expected under oligotrophic conditions to extreme eutrophic conditions by varying only growth efficiency, $\varepsilon$ (Fig. 2).

Based on Eq. (4), the rate of reactions (1) and (2) are expressed by $\left(\mathrm{mmol} \mathrm{m}^{-3} \mathrm{~d}^{-1}\right)$,

$r_{1}=v_{1} C_{\mathfrak{S}_{1}}=v^{*} \varepsilon_{1}^{2}\left(1-\varepsilon_{1}^{2}\right)\left(\frac{C_{\mathrm{CH}_{2} \mathrm{O}}}{C_{\mathrm{CH}_{2} \mathrm{O}}+\kappa^{*} \varepsilon_{1}^{4}}\right)\left(\frac{C_{\mathrm{NH}_{3}}}{C_{\mathrm{NH}_{3}}+\kappa^{*} \varepsilon_{1}^{4}}\right) C_{\mathfrak{S}_{1}}$ $r_{2}=v_{2} C_{\mathscr{S}_{2}}=v^{*} \varepsilon_{2}^{2}\left(1-\varepsilon_{2}^{2}\right)\left(\frac{C_{\mathscr{S}_{T}}}{C_{\mathcal{S}_{T}}+\kappa^{*} \varepsilon_{2}^{4}}\right) C_{\mathscr{S}_{2}}$.

Equations (6) and (7) allow us to explore reaction rates for different community compositions by varying only $\varepsilon_{1}$ and $\varepsilon_{2}$ between 0 and 1 . Of course, other mathematical functions could be used in place of Eq. (4), but this is not our primary interest for this manuscript, but it is an interesting topic that warrants further research. For instance, we use the same effective Monod constant, $\kappa^{*} \varepsilon_{i}^{4}$, regardless of substrate type in Eqs. (6) or (7), which could likely be improved, nor do we account for other complexities of cellular growth (Ferenci, 1999; Smith et al., 2009).

\subsection{Free energy and entropy balance equations}

A standard entropy balance around the control volume (Fig. 1, red dashed boundary) takes the general form,

$\frac{d S}{d t}=\sum_{k=1}^{6} F_{\Omega}(k) \hat{S}_{k}+\frac{\dot{Q}}{T}+\dot{\sigma}_{I}$

where $S$ is system entropy per unit area $\left(\mathrm{J} \mathrm{m}^{-2}{ }^{\circ} \mathrm{K}^{-1}\right), \hat{S}_{k}$ is the molar entropy $\left(\mathrm{J} \mathrm{mmol}^{-1} \quad{ }^{\circ} \mathrm{K}^{-1}\right)$ of constituent $k$ transported across the boundary by flux $F_{\Omega}\left(\mathrm{mmol} \mathrm{m}^{-2} \mathrm{~d}^{-1}\right), \dot{Q}$ is the heat flux into the system $\left(\mathrm{J} \mathrm{m}^{-2} \mathrm{~d}^{-1}\right), T$ is temperature $\left({ }^{\circ} \mathrm{K}\right)$ and $\dot{\sigma}_{\mathrm{I}}$ is the internal entropy production rate per unit area of water column $\left(\mathrm{J} \mathrm{m}^{-2} \mathrm{~d}^{-1}{ }^{\circ} \mathrm{K}^{-1}\right)$. Under steady state conditions, $d S / d t=0$ and internal entropy production equals the entropy transported into the control volume via mass and heat flux. In this manuscript, we are solely concerned with internal entropy production, $\dot{\sigma}_{\mathrm{I}}$, and we will assume homogeneity and isothermal conditions prevail in each box. Unlike other analyses (Meysman and Bruers, 2007), we include entropy of mixing within the system boundary (Fig. 1), as biological systems can significantly alter transport characteristics (Erwin, 2008; Jones et al., 1994); however, we will not consider direct alteration of transport coefficients in our analysis.

For our two box model, internal entropy production occurs via destruction of chemical potential via reactions (1) and (2), $\dot{\sigma}_{r}$, and by entropy of mixing, $\dot{\sigma}_{F}$, associated with relaxing chemical potential gradients between boxes [1] and [2] and their associated boundaries. For chemical reactions, entropy production per unit area in a given box with depth $h(\mathrm{~m})$ is readily determined under constant pressure and temperature from the Gibbs free energy of reaction, $\Delta \mathrm{G}_{\mathrm{r}}$, reaction rate, $r$, and absolute temperature, $T$, as given by (Eu, 1992 pp. 131141) $\left(\mathrm{J} \mathrm{m}^{-2} \mathrm{~d}^{-1}{ }^{\circ} \mathrm{K}^{-1}\right)$,

$\dot{\sigma}_{r_{i}}[j]=-\frac{h[j]}{T} r_{i}[j] \Delta \mathrm{G}_{\mathrm{r} i}[j]$,

where $[j]$ corresponds to either box [1] or [2] and $i$ to either reactions (1) or (2). While Gibbs free energy of reaction is usually straight forward to calculate for a given reaction 
stoichiometry, both reactions (1) and (2) require some discussion because both involve synthesis or decomposition of living biomass, or more generally, what we refer to as biological structure.

Living organisms are often thought to be very low entropy structures because they are highly order systems. However, statistical thermodynamic calculations show that entropy contributions due to patterns only become significant compared to the entropy of the substrate the pattern is written in (i.e., DNA, protein) when ordering occurs at the atomic scale (Morrison, 1964). Based on information content of a bacterial cell (Morowitz, 1955; Johnson, 1970), entropy reduction due to molecular order is trivial compared to entropy contributions of substrate synthesis (Morrison, 1964). Hence the total entropy of a random sequence of polymerized amino acids is only slightly greater than a specific amino acid sequence that gives rise to a functioning protein. Furthermore, both theoretical calculations and empirical data show that bacteria and yeast have higher standard specific entropies than glucose (Battley, 1999a, b, 2003). Biological structure has a higher specific entropy than "simple" growth substrates, and it can be shown that the standard Gibbs free energy of reaction for synthesizing bacteria or yeast from glucose, ammonia, phosphate and sulfate, without $\mathrm{CO}_{2}$ production (i.e., $\varepsilon=1$ ), is slightly less than zero, so is a reaction that can occur spontaneously (Vallino, 2010). Although poorly appreciated, the "order" ascribed to biological systems is simply not thermodynamically important compared to their bulk composition. Hence, it is thermodynamically possible for reaction (1) to proceed without additional free energy input with $\varepsilon_{1}=1$. However, as mentioned above, reaction rates are also constrained by thermodynamics as Gibbs free energy of reaction approaches zero. For a reaction to proceed at high rate it must proceed irreversibly; consequently, organisms whose growth efficiency is less than $100 \%$ can grow faster than those operating at very high efficiencies. The diminishing returns of high growth efficiency is embed in our growth kinetics equation, as plotting Eq. (5) as a function of $\varepsilon$ exhibits an optimum, so that maximum specific growth rate under nutrient saturation $\left(\left.\frac{\mathrm{d} \mu}{\mathrm{d} \varepsilon}\right|_{C_{j} \rightarrow \infty}=0\right)$ occurs as $\varepsilon \rightarrow \sqrt{3 / 5} \approx 0.77$.

The Gibbs free energy change for reactions (1) and (2) can be expressed as a linear combination of biosynthesis and $\mathrm{CH}_{2} \mathrm{O}$ oxidation, as given by $\left(\mathrm{J} \mathrm{mmol}^{-1}\right)$,

$$
\begin{aligned}
& \Delta \mathrm{G}_{\mathrm{r} 1}=\left(1-\varepsilon_{1}\right) \Delta \mathrm{G}_{\mathrm{Ox}}^{\circ}+\varepsilon_{1} \Delta \mathrm{G}_{\mathcal{G}}^{\circ} \\
& +R T \ln \left(10^{6\left(1-\varepsilon_{1}(1-\rho)\right)} \frac{C_{\mathrm{H}_{2} \mathrm{CO}_{3}}^{1-\varepsilon_{1}} C^{\varepsilon_{1}}{ }^{\xi_{1}}}{C_{\mathrm{CH}_{2} \mathrm{O}} C_{\mathrm{O}_{2}}^{1-\varepsilon_{1}} C_{\mathrm{NH}_{3}}^{\varepsilon_{1} \rho}}\right) \\
& \Delta \mathrm{G}_{\mathrm{r} 2}=\left(1-\varepsilon_{2}\right) \Delta \mathrm{G}_{\mathrm{Ox}}^{\circ}-\left(1-\varepsilon_{2}\right) \Delta \mathrm{G}_{\mathrm{g}}^{\circ} \\
& +R T \ln \left(10^{6\left(1-\varepsilon_{2}-\rho\left(1-\varepsilon_{2}\right)\right)} \frac{C_{\mathrm{H}_{2} \mathrm{CO}_{3}}^{1-\varepsilon_{2}} C_{\mathrm{NH}_{3}}^{\left(1-\varepsilon_{2}\right) \rho} C_{\mathscr{S}_{2}}^{\varepsilon_{2}}}{C_{\mathcal{S}_{T}} C_{\mathrm{O}_{2}}^{1-\varepsilon_{2}}}\right),
\end{aligned}
$$

Table 1. Model fixed parameter values.

\begin{tabular}{llr}
\hline Parameter & Description & Value (units) \\
\hline$v^{*}$ & Universal kinetic parameter & $350\left(\mathrm{~d}^{-1}\right)$ \\
$\kappa^{*}$ & Universal kinetic parameter & $5000\left(\mathrm{mmol} \mathrm{m}^{-3}\right)$ \\
$D$ & Diffusion coefficient & $1 \times 10^{-4}\left(\mathrm{~m}^{2} \mathrm{~d}^{-1}\right)$ \\
$\ell$ & Characteristic length & $2.5 \times 10^{-5}(\mathrm{~m})$ \\
$h[1], h[2]$ & Depth of boxes [1] and [2] & $10(\mathrm{~m})$ \\
$\rho$ & N to C ratio of $\mathcal{S}_{i}$ & $1 / 6($ atomic $)$ \\
$T$ & Temperature & $293.15\left({ }^{\circ} \mathrm{K}\right)$ \\
$\mathrm{pH}$ & pH & 8.1 \\
$I_{S}$ & Ionic Strength & $0.7(\mathrm{M})$ \\
$\Delta G_{\mathrm{Ox}}^{\circ}$ & Standard Gibbs free energy & $-498.4\left(\mathrm{~J} \mathrm{mmol}^{-1}\right)$ \\
$\Delta \mathrm{G}_{\mathcal{S}}^{\circ}$ & of $\mathrm{CH}_{2} \mathrm{O}$ oxidation to $\mathrm{H}_{2} \mathrm{CO}_{3}$ & $0\left(\mathrm{~J} \mathrm{mmol}^{-1}\right)$ \\
& Standard Gibbs free energy & \\
& of $\dot{S}^{\circ}$ synthesis from $\mathrm{CH}_{2} \mathrm{O}$ & \\
\hline
\end{tabular}

where $R$ is the ideal gas constant $\left(8.3145 \times 10^{-3} \mathrm{~J} \mathrm{mmol}^{-1}\right.$ $\left.{ }^{\circ} \mathrm{K}^{-1}\right), \Delta \mathrm{G}_{\mathrm{Ox}}^{\circ}$ is the standard Gibbs free energy of $\mathrm{CH}_{2} \mathrm{O}$ oxidation by $\mathrm{O}_{2}$ to $\mathrm{H}_{2} \mathrm{CO}_{3}\left(-498.4 \mathrm{~J} \mathrm{mmol}^{-1}\right)$ and $\Delta \mathrm{G}_{\mathcal{G}}^{\circ}$ is the standard Gibbs free energy for biological structure synthesis from $\mathrm{CH}_{2} \mathrm{O}$ and $\mathrm{NH}_{3}$, which is set to zero for our study because it is negligibly small (Vallino, 2010). We use the approach of Alberty $(2003,2006)$ to calculate the standard Gibbs free energy of reaction, $\Delta \mathrm{G}_{\mathrm{Ox}}^{\circ}$, which accounts for proton dissociation equilibria between chemical species $\left(\mathrm{CO}_{2}+\mathrm{H}_{2} \mathrm{O} \leftrightarrow \mathrm{H}_{2} \mathrm{CO}_{3} \leftrightarrow \mathrm{H}^{+}+\mathrm{HCO}_{3}^{-}\right.$, etc. $)$at a pH of 8.1 and temperature of $293.15^{\circ} \mathrm{K}$. Ionic strength $\left(\mathrm{I}_{S}=0.7 \mathrm{M}\right)$ is used to estimate activity coefficients, so that concentrations can be used in the logarithmic correction terms in Eqs. (10) and (11) instead of activities as described by Alberty (2003), and the $10^{6}$ terms convert $\mu$ molar (or $\mathrm{mmol} \mathrm{m}^{-3}$ ) to standard molar concentrations.

Entropy of mixing is readily calculated between boxes and boundaries based on flux and chemical potential obtained from concentration differences between boxes (Meysman and Bruers, 2007; Kondepudi and Prigogine, 1998). For our simple model, we only permit diffusive transport between boxes and boundaries, so a material flux of chemical species $k$ from box or boundary $[i]$ to box or boundary $[j]$ is given by $\left(\mathrm{mmol} \mathrm{m}^{-2} \mathrm{~d}^{-1}\right)$,

$$
F_{i, j}(k)=-\frac{D}{\ell}\left(C_{k}[j]-C_{k}[i]\right) \beta_{i, j}(k),
$$

where $\ell$ is a characteristic length scale for diffusion $\left(2.5 \times 10^{-5} \mathrm{~m}\right), D$ is the diffusion coefficient $\left(1 \times 10^{-4} \mathrm{~m}^{2}\right.$ $\left.\mathrm{d}^{-1}\right)$ and $\beta_{i, j}(k)$ is 1 if flux of compound $k$ is allowed between box or boundary $[i]$ and $[j]$; otherwise it is 0 . Technically, Eq. (12) should be based on chemical potential gradient; however, this can be reasonably approximated by the concentration gradient in this case. The product of flux and chemical potential differences, $\Delta \mu_{i, j}(k)$, divided by temperature gives the entropy production per unit area for mixing 
between box $[i]$ to $[j]$ for chemical species $k$, as follows $\left(\mathrm{J} \mathrm{m}^{-2} \mathrm{~d}^{-1}{ }^{\circ} \mathrm{K}^{-1}\right)$

$$
\begin{aligned}
\dot{\sigma}_{F_{i, j}(k)} & =F_{i, j}(k) \frac{\Delta \mu_{i, j}(k)}{T} \\
& =-\frac{D}{\ell}\left(C_{k}[j]-C_{k}[i]\right) \beta_{i, j}(k) R \ln \left(\frac{C_{k}[i]}{C_{k}[j]}\right)
\end{aligned}
$$

where again activities have been approximated by concentrations. Given concentrations of the six constituents, $\mathrm{CH}_{2} \mathrm{O}$, $\mathrm{O}_{2}, \mathrm{H}_{2} \mathrm{CO}_{3}, \mathrm{NH}_{3},{ }_{1}$ and ${ }_{2}$ corresponding to $k=1, \ldots 6$, along with the growth efficiencies $\varepsilon_{1}$ and $\varepsilon_{2}$ in each box, internal entropy production per unit water-column area associated with reactions and mixing can be calculated from Eqs. (6-13) and is given by $\left(\mathrm{J} \mathrm{m}^{-2} \mathrm{~d}^{-1 \circ} \mathrm{K}^{-1}\right)$,

$$
\begin{aligned}
& \dot{\sigma}_{\mathrm{I}}[1]=\dot{\sigma}_{r_{1}}[1]+\dot{\sigma}_{r_{2}}[1]+\sum_{k=1}^{6}\left(\dot{\sigma}_{F_{0,1}(k)}+\dot{\sigma}_{F_{1,2}(k)}\right) \\
& \dot{\sigma}_{\mathrm{I}}[2]=\dot{\sigma}_{r_{1}}[2]+\dot{\sigma}_{r_{2}}[2]+\sum_{k=1}^{6}\left(\dot{\sigma}_{F_{1,2}(k)}+\dot{\sigma}_{F_{2,3}(k)}\right) \\
& \dot{\sigma}_{\mathrm{I}}=\dot{\sigma}_{r_{1}}[1]+\dot{\sigma}_{r_{2}}[1]+\dot{\sigma}_{r_{1}}[2]+\dot{\sigma}_{r_{2}}[2] \\
& \quad+\sum_{k=1}^{6}\left(\dot{\sigma}_{F_{0,1}(k)}+\dot{\sigma}_{F_{1,2}(k)}+\dot{\sigma}_{F_{2,3}(k)}\right),
\end{aligned}
$$

where $\dot{\sigma}_{I}[1]$ is entropy production associated with box [1] (blue dashed box, Fig. 1), $\dot{\sigma}_{\mathrm{I}}[2]$ is entropy production associated with box [2] (green dashed box, Fig. 1) and $\dot{\sigma}_{\mathrm{I}}$ is total internal entropy production associated with both boxes (red dashed box, Fig. 1). We note that $\dot{\sigma}_{\mathrm{I}}[1]$ and $\dot{\sigma}_{\mathrm{I}}[2]$ will server merely as numerical objective functions for local optimization and could be defined differently, especially with respect to how entropy of mixing flux between boxes, $\dot{\sigma}_{F_{1,2}(k)}$, could be partitioned. We have chosen to include $\dot{\sigma}_{F_{1,2}(k)}$ in both $\dot{\sigma}_{\mathrm{I}}[1]$ and $\dot{\sigma}_{\mathrm{I}}[2]$ because state changes in either box directly alters the $F_{1,2}(k)$ flux; consequently, $\dot{\sigma}_{I}=$ $\dot{\sigma}_{\mathrm{I}}[1]+\dot{\sigma}_{\mathrm{I}}[2]-\sum_{k=1}^{6} \dot{\sigma}_{F_{1,2}(k)}$. For comparing internal entropy production between local versus global optimization below, only $\dot{\sigma}_{\mathrm{I}}$ defined by Eq. (16) is relevant.

\subsection{Transport equations, optimization and numerical routines}

To obtain changes in chemical constituents over time for a given set of boundary conditions, a mass balance model is constructed based on in-and-out fluxes and production rates by reactions (1) and (2) for each constituent $k$ in boxes [1] and [2], which takes the general form,

$\frac{d C_{k}[i]}{d t}=\left(F_{i-1, i}(k)-F_{i, i+1}(k)\right) / h[i]+\boldsymbol{\Lambda}_{k}[i] r[i]$ for $i=1,2(17)$

where the brackets, $[i]$, following a variable denote the boxboundary location with [0] being the upper boundary and [3] being the lower boundary (Fig. 1). Elements of the $1 \times 2 \mathrm{vec}-$ tor $\boldsymbol{\Lambda}_{k}$ are the stoichiometric coefficients for compound $k$ obtained from reactions (1) and (2), and $\boldsymbol{r}$ is a $2 \times 1 \mathrm{vec}-$ tor of reaction rates, $\left[r_{1} r_{2}\right]^{T}$, given by Eqs. (6) and (7). The full model equations are detailed in Appendix A for $k=\mathrm{CH}_{2} \mathrm{O}, \mathrm{O}_{2}, \mathrm{H}_{2} \mathrm{CO}_{3}, \mathrm{NH}_{3}, \mathcal{S}_{2}$ in the two boxes, and parameter values used for all simulations are given in Table 1.

We have intentionally designed our biogeochemistry model to contain only a few transport related parameters $(D$, $\ell, h)$ and effectively only two adjustable biological parameters per box, giving a total of four control variables for the two box model: $\varepsilon_{1}$ [1], $\varepsilon_{2}$ [1], $\varepsilon_{1}$ [2], and $\varepsilon_{2}$ [2]. Because choosing a value for $\varepsilon_{i}[j]$ effectively selects the kinetic characteristics of the community in box $[j]$, we can examine how entropy production changes as a function of community composition, which has a collective respiration given by $\sum_{i=1}^{2}\left(1-\varepsilon_{i}[j]\right) r_{i}[j]$. More importantly for this study, the values of $\varepsilon_{1}$ [1], $\varepsilon_{2}$ [1], $\varepsilon_{1}[2]$, and $\varepsilon_{2}$ [2] that maximize entropy production can be determined by numerical analysis, and via Eqs. (6) and (7) the biogeochemistry associated with the MEP state is defined. For a zero dimensional system, a variation of this approach has been used to determine how biogeochemistry develops over time (Vallino, 2010); however, for a system that has one or more spatial dimensions, a choice needs to be made regarding local versus global optimization of entropy production. For the two-box model, entropy production can be asynchronously maximized locally (i.e., in each box), with the cost functions defined by Eqs. (14) and (15) as given by,

$$
\begin{aligned}
& \text { Maximize } \\
& \varepsilon_{1}[1], \varepsilon_{2}[1]
\end{aligned} \quad \dot{\sigma}_{\mathrm{I}}[1] \quad \text { and } \quad \begin{gathered}
\text { Maximize } \\
\varepsilon_{1}[2], \varepsilon_{2}[2]
\end{gathered} \quad \dot{\sigma}_{\mathrm{I}}[2] .
$$

Globally (i.e, across both boxes synchronously), the optimization is defined by the cost function given by Eq. (16), as given by,

$$
\underset{,}{\operatorname{Maximize}} \varepsilon_{2}[1], \varepsilon_{1}[2], \varepsilon_{2}[2] \quad \dot{\sigma}_{\mathrm{I}}
$$

where both optimizations are bounded within the tesseract, $0 \leq \varepsilon_{i}[j] \leq 1$. Of course, local maximization, as given by Eq. (18), requires an iterative (i.e., asynchronous) approach, because changing the conditions in one box alters the optimal solution for the other. In contrast, global optimization given by Eq. (19) is mathematically well posed, but the parameter space is larger (4-D vs. 2-D in this case). For local optimization, Eq. (18), we have chosen to associate the entropy of mixing terms that directly contribute to the box being optimized. While other partitions of mixing entropy can be envisioned, we will demonstrate below that the entropy of mixing terms represent very minor contributions to internal entropy production, and simulations with mixing entropies completely removed had insignificant impact on the results and conclusions. 
Table 2. Model initial conditions (for boxes [1] and [2]) and Dirichlet boundary conditions (for [0] and [3]) used for all model simulations.

\begin{tabular}{lcccccc}
\hline $\begin{array}{l}\text { Box or } \\
\text { boundary }\end{array}$ & \multicolumn{7}{c}{ Variable Concentrations $\left(\mathrm{mmol} \mathrm{m}^{-3}\right)$} \\
\hline & $C_{\mathrm{CH}_{2} \mathrm{O}}[i]$ & $C_{\mathrm{O}_{2}}[i]$ & $C_{\mathrm{H}_{2} \mathrm{CO}_{3}[i]}$ & $C_{\mathrm{NH}_{3}}[i]$ & $C_{\mathcal{S}_{1}}[i]$ & $C_{\mathcal{S}_{2}}[i]$ \\
{$[0]$} & 100 & 290 & 2000 & - & - & - \\
{$[1]$} & 100 & 290 & 2000 & 1.0 & 0.1 & 0.1 \\
{$[2]$} & 100 & 290 & 2000 & 1.0 & 0.1 & 0.1 \\
{$[3]$} & $-*$ & - & - & 1.0 & - & - \\
\hline
\end{tabular}

* Indicates variable is not allowed to cross boundary (i.e., $\beta_{i, j}(k)=0$ in Eq. (12)).

While optimization of Eqs. (18) and (19) can be conducted for the transient problem, Eq. (17), over a specified time interval (Vallino, 2010), we are primarily interested in how spatial optimization alters MEP solutions. Consequently, we are only interested in steady state (SS) solutions to Eq. (17). Typically, Newton's method, or a variation thereof, is used to solve for SS solutions to Eq. (17); however, employing several variations to Newton's method including a line search technique with trust region (Bain, 1993) was found to fail in some subspaces of $0 \leq \varepsilon_{i}[j] \leq 1$. An approach based on interval arithmetic (Kearfott and Novoa, 1990; Kearfott, 1996) was also developed, but proved to be too computationally burdensome. The most robust approach found was to integrate the ODEs, Eq. (17), forward in time using a high precision block implicit method (Brugnano and Magherini, 2004) from a specified initial condition (Table 2) until $\frac{1}{2}(\mathrm{~d} C / \mathrm{dt})^{T}(\mathrm{~d} \boldsymbol{C} / \mathrm{dt}) \leq \zeta$, where $\boldsymbol{C}$ is a vector of concentrations and $\zeta$ was set to $10^{-8} \mathrm{mmol} \mathrm{m}^{-3} \mathrm{~d}^{-1}$. If a steady state solution failed to be obtained after $10^{6}$ days of integration time, the point was flagged and removed from the search, but this rarely occurred.

Numerical solution to Eq. (19) was obtained by using VTDIRECT (He et al., 2009), which employs a parallel version of a Lipschitzian direct search algorithm (Jones et al., 1993) to find a function's global optimum without using function derivatives. We also used VTDIRECT to solve Eq. (18), but we implemented an iterative approach, where first box [1] was optimized for given values of $\varepsilon_{1}$ [2] and $\varepsilon_{2}$ [2], then box [2] was optimized given $\varepsilon_{1}[1]$ and $\varepsilon_{2}$ [1] from the previous optimization of box [1]; this iteration proceeded until $\|\boldsymbol{\varepsilon}[j]-\hat{\boldsymbol{\varepsilon}}[j]\| \leq 10^{-9}$ for each box, where \|\| is the Euclidian norm and the vector $\hat{\boldsymbol{\varepsilon}}\left(\hat{\boldsymbol{\varepsilon}}=\left[\hat{\varepsilon}_{1} \hat{\varepsilon}_{2}\right]^{T}\right)$ is the value of $\boldsymbol{\varepsilon}$ from the previous iteration. We note that the local optimization search converged to the same solution regardless of the initial choice of $\varepsilon_{1}$ [2] or $\varepsilon_{2}$ [2].

\section{Results and discussion}

\subsection{Model characteristics}

For any specified point in $\varepsilon_{i}[j]$-space, a solution to Eq. (17) can be found. For instance, Fig. 3 illustrates the transient dynamics to steady state for the point $\left(\varepsilon_{1}[1], \varepsilon_{2}[1], \varepsilon_{1}[2]\right.$, $\left.\varepsilon_{2}[2]\right)=(0.1,0.05,0.1,0.05)$ with the parameters and initial and boundary conditions used throughout this study (Tables 1 and 2, respectively). For this particular solution, SS internal entropy production dominates in box [1] $\left(590 \mathrm{~J} \mathrm{~m}^{-2}\right.$ $\mathrm{d}^{-1}{ }^{\circ} \mathrm{K}^{-1}$, blue bounding box in Fig. 1), as compared to box [2] (41.8 $\mathrm{J} \mathrm{m}^{-2} \mathrm{~d}^{-1}{ }^{\circ} \mathrm{K}^{-1}$, green bounding box in Fig. $1)$, and entropies associated with mixing between boundary [0] and box [1], box [1] and box[2], and box [2] and boundary [3] are 14.6, 0.436 and $0.00\left(\mathrm{~J} \mathrm{~m}^{-2} \mathrm{~d}^{-1} \quad{ }^{\circ} \mathrm{K}^{-1}\right)$, respectively. Due to the significant amount of free energy release in oxidation of reduced organic compounds, entropy of mixing, $\dot{\sigma}_{F}$, is a small fraction of the entropy production associated with reactions, $\dot{\sigma}_{r}$. To demonstrate this more generally, we randomly chose 100000 points within the 4-D $\varepsilon_{i}[j]$-space and calculated the steady state solution to Eq. (17) and associated entropy terms, which shows that entropy of mixing is at most $7.2 \%$ of total entropy production and for most cases much less than that (Fig. 4a). Only 310 points out of 100310 Monte Carlo simulations did not attain a SS solution within $10^{6}$ days.

An interesting aspect of the model is that the amount of nitrogen extracted from the sediments, or boundary [3], depends on community composition, because changing values of $\varepsilon_{i}[j]$ dramatically affects the total standing SS nitrogen within boxes [1] and [2], calculated as $\left(\mathrm{mmol} \mathrm{N} \mathrm{m}^{-2}\right)$,

$N_{\text {Total }}=\sum_{i=1}^{2} h[i]\left(C_{\mathrm{NH}_{3}}[i]+\rho\left(C_{\mathcal{S}_{1}}[i]+C_{\mathcal{S}_{2}}[i]\right)\right)$,

which is evident in the results from the 100000 Monte Carlo simulations (Fig. 4b). For any given entropy production defined by Eq. (16), numerous SS solutions can be found that differ in location within $\varepsilon_{i}[j]$-space and exhibit differences of up to four orders of magnitude in $N_{\text {Total }}$ (Fig. 4b). Variation in $C_{\mathcal{B}_{T}}$ in the vicinity of MEP may explain how biomass 

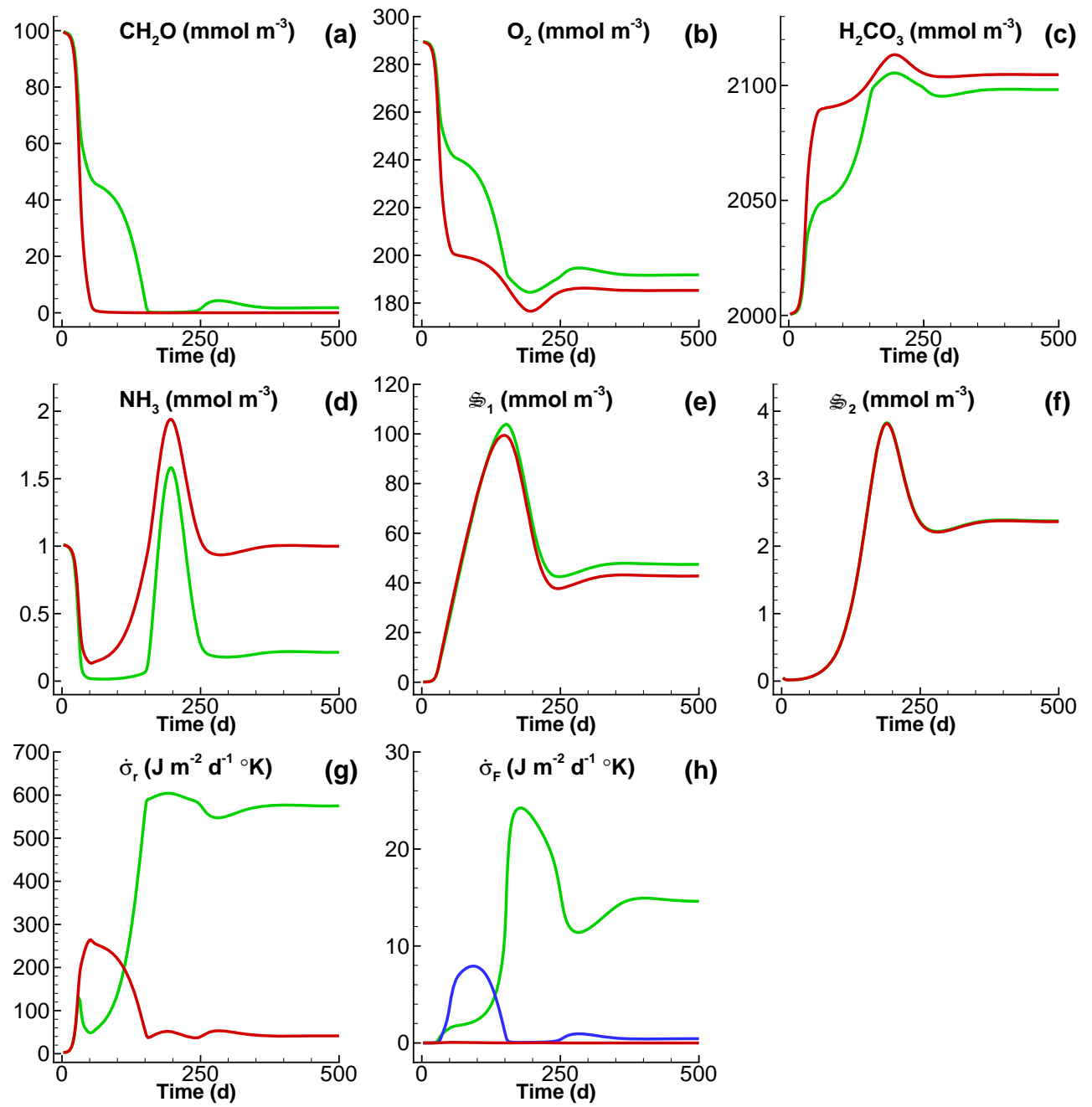

Fig. 3. Concentration of state variables (a-f) and entropy production from reactions (g) and mixing (h) for the point $\left(\varepsilon_{1}[1], \varepsilon_{2}[1], \varepsilon_{1}[2]\right.$, $\left.\varepsilon_{2}[2]\right)=(0.1,0.05,0.1,0.05)$ based on Eq. (17). In (a-g), green line represents variables in box [1], while red line is for variables in box [2]. The green, blue and red lines in (h) correspond to entropy of mixing between boundary [0] and box [1], box [1] and box [2], and box [2] and boundary [3], respectively.

specific entropy production can change with ecosystem maturity (Aoki, 2008). While the vast majority of solutions result in an $N_{\text {Total }}$ less than $10^{4} \mathrm{mmol} \mathrm{m}^{-2}, 33$ solutions produced high to extremely high $N_{\text {Total }}$ values. Examination of community kinetics that lead to high $N_{\text {Total }}$ values reveals an apparent necessary condition that the growth efficiency of reaction (2), $\varepsilon_{2}[\mathrm{j}]$, in both boxes [1] and [2] must be less than 0.02 (Fig. 5). Inspection of the transient solution reveals that high $\dot{B}_{1}$ concentration develops due to extremely slow growth rates of ${ }_{2}$ caused by small $\varepsilon_{2}[\mathrm{j}]$ values (data not shown). Over time, $\mathscr{S}_{2}$ develops sufficient concentration to place "top down" control on 1 , but this leads to elevated SS concentrations of both $\mathscr{2}_{1}$ and $\mathscr{2}_{2}$.

Inspection of total entropy production by reactions (1) and (2) from the Monte Carlo simulations reveals that the top 20 SS solutions have total internal entropy production dis- tributed over a narrow range from 642.22 to $643.07 \mathrm{~J} \mathrm{~m}^{-2}$ $\mathrm{d}^{-1} \quad{ }^{\circ} \mathrm{K}^{-1}$; however, the corresponding $\varepsilon_{i}[j]$ points have a much broader distribution over $\varepsilon_{i}[j]$-space (Table 3 ), which produce significant differences in transient dynamics and SS standing stocks (Fig. 6). Most significant are differences in SS standing stocks for biological structures $\mathscr{D}_{1}$ and that can range from 52 to 19020 and from 2.2 to $174 \mathrm{mmol} \mathrm{m}^{-2}$ in box [1], respectively. These state variations that have nearly identical entropy productions illustrate, at least qualitatively, an important concept in MEP theory (Dewar, 2005, 2009), which is there should be many micropath solutions that produce the same macropath (or MEP) state. Since MEP theory rests on probabilities (Dewar, 2009; Lorenz, 2003), slight variations in entropy production exhibited by the top SS entropy producing solutions (Table 3) can be viewed as interchangeable, since any real system is subject to noise that 
Table 3. Values in 4-D $\varepsilon_{i}[j]$-space that correspond to the 20 highest internal entropy production rates, $\dot{\sigma}_{I}$ Eq. $(16),\left(\mathrm{J} \mathrm{m}^{-2} \mathrm{~d}^{-1} \quad{ }^{\circ} \mathrm{K}^{-1}\right)$ from the 100000 Monte Carlo simulations. Here $\dot{\sigma}_{\boldsymbol{r}}=\dot{\sigma}_{r_{1}}[1]+\dot{\sigma}_{r_{2}}[1]+\dot{\sigma}_{r_{1}}[2]+\dot{\sigma}_{r_{2}}[2]$ and $\dot{\sigma}_{\boldsymbol{F}}=\sum_{k=1}^{6}\left(\dot{\sigma}_{F_{0,1}(k)}+\dot{\sigma}_{F_{1,2}(k)}+\dot{\sigma}_{F_{2,3}(k)}\right)$ are total internal entropy productions from reactions and mixing, respectively.

\begin{tabular}{rrrrrrr}
\hline$\varepsilon_{1}[1]$ & $\varepsilon_{2}[1]$ & $\varepsilon_{1}[2]$ & $\varepsilon_{2}[2]$ & $\dot{\sigma}_{\boldsymbol{r}}$ & $\dot{\sigma}_{\boldsymbol{F}}$ & $\dot{\sigma}_{I}$ \\
\hline 0.115840 & 0.008848 & 0.19774 & 0.001492 & 602.46 & 40.607 & 643.067 \\
0.081216 & 0.008126 & 0.14751 & 0.004026 & 599.40 & 43.66 & 643.060 \\
0.040506 & 0.004444 & 0.45347 & 0.008376 & 596.74 & 46.319 & 643.059 \\
0.034556 & 0.013810 & 0.63265 & 0.005105 & 601.00 & 42.057 & 643.057 \\
0.037706 & 0.010242 & 0.38227 & 0.018611 & 604.91 & 38.142 & 643.052 \\
0.012111 & 0.003315 & 0.57708 & 0.009786 & 596.47 & 46.576 & 643.046 \\
0.022522 & 0.018299 & 0.08346 & 0.008856 & 605.33 & 37.708 & 643.038 \\
0.125490 & 0.018242 & 0.30648 & 0.002544 & 610.46 & 32.566 & 643.026 \\
0.071504 & 0.023712 & 0.82380 & 0.024850 & 612.19 & 30.783 & 642.973 \\
0.029651 & 0.004722 & 0.03499 & 0.028105 & 613.23 & 29.699 & 642.929 \\
0.075518 & 0.035487 & 0.86522 & 0.014358 & 613.77 & 29.151 & 642.921 \\
0.048038 & 0.037938 & 0.78268 & 0.016527 & 614.59 & 28.273 & 642.863 \\
0.071063 & 0.024790 & 0.23527 & 0.032890 & 614.71 & 28.149 & 642.859 \\
0.118860 & 0.030821 & 0.90396 & 0.007209 & 615.21 & 27.641 & 642.851 \\
0.107290 & 0.035433 & 0.54022 & 0.006473 & 615.57 & 27.255 & 642.825 \\
0.120840 & 0.032660 & 0.10968 & 0.000561 & 615.69 & 27.126 & 642.816 \\
0.257120 & 0.013008 & 0.75947 & 0.001172 & 617.01 & 25.638 & 642.648 \\
0.114720 & 0.036114 & 0.09940 & 0.021301 & 617.89 & 24.576 & 642.466 \\
0.095344 & 0.030462 & 0.18539 & 0.996260 & 618.96 & 23.323 & 642.283 \\
0.057887 & 0.044734 & 0.98099 & 0.033569 & 618.67 & 23.554 & 642.224 \\
\hline
\end{tabular}

would make the small differences in $\dot{\sigma}_{\text {I }}$ indistinguishable. For our model system, there are clearly multiple solutions that give rise to what is effectively the same MEP state.

\subsection{Global versus Local MEP solutions}

The global MEP solution obtained by maximizing total internal entropy production, $\dot{\sigma}_{\mathrm{I}}$ Eq. (16), over the whole domain (red dashed box, Fig. 1) by simultaneously varying $\varepsilon_{1}$ [1], $\varepsilon_{2}$ [1], $\varepsilon_{1}$ [2] and $\varepsilon_{2}$ [2] as given by Eq. (19) is $643.10 \mathrm{~J} \mathrm{~m}^{-2}$ $\mathrm{d}^{-1}{ }^{\circ} \mathrm{K}^{-1}$ (Table 4). Because of the small 4-D parameter space of our model, this solution was almost located by the Monte Carlo simulations (Table 3). To examine the solution in the vicinity of the global maximum, we plot $\dot{\sigma}_{\mathrm{I}}[1]$, Eq. (14), as a function of $\varepsilon_{1}$ [1] and $\varepsilon_{2}$ [1] while holding $\varepsilon_{1}$ [2] and $\varepsilon_{2}$ [2] fixed at their global optimum values, and vice versa for $\dot{\sigma}_{I}$ [2] (Fig. 7). It is clear from this plot that $\dot{\sigma}_{I}[1]$ of $642.96 \mathrm{~J} \mathrm{~m}^{-2} \mathrm{~d}^{-1} \quad{ }^{\circ} \mathrm{K}^{-1}$ is near the $\dot{\sigma}_{\mathrm{I}}[1]$ maximum for box [1] given $\varepsilon_{1}$ [2] and $\varepsilon_{2}$ [2] (Fig. 7a, light gray point); however, it is also evident that $\dot{\sigma}_{\mathrm{I}}[2]$ that contributes $0.142 \mathrm{~J} \mathrm{~m}^{-2} \mathrm{~d}^{-1}$ ${ }^{\circ} \mathrm{K}^{-1}$ (Fig. 7b, light gray point) to the global solution is far removed from the maximum $\dot{\sigma}_{I}[2]$ possible in box [2] that could be attained given $\varepsilon_{1}[1]$ and $\varepsilon_{2}[1]$, which is approximately $215 \mathrm{~J} \mathrm{~m}^{-2} \mathrm{~d}^{-1}{ }^{\circ} \mathrm{K}^{-1}$. This result indicates that the global optimum does not correspond to local optimums. Entropy productions associated with mixing, Eq. (13), summed
Table 4. Global and local MEP solutions $\left(\mathrm{J} \mathrm{m}^{-2} \mathrm{~d}^{-1}{ }^{\circ} \mathrm{K}^{-1}\right)$ based on solutions to Eqs. (19) and (18), respectively.

\begin{tabular}{lrr}
\hline Variable & Global, Eq. (19) & Local, Eq. (18) \\
\hline$\varepsilon_{1}[1]$ & 0.0754 & 0.0991 \\
$\varepsilon_{2}[1]$ & 0.0123 & 0.0352 \\
$\varepsilon_{1}[2]$ & 0.2222 & 0.0997 \\
$\varepsilon_{2}[2]$ & 0.9998 & 0.1100 \\
$\dot{\sigma}_{\boldsymbol{r}}[1]$ & 611.64 & 225.92 \\
$\dot{\sigma}_{\boldsymbol{r}}[2]$ & 0.139 & 204.97 \\
$\sum_{k=1}^{6} \dot{\sigma}_{F_{0,1}(k)}$ & 31.32 & 3.25 \\
$\sum_{k=1}^{6} \dot{\sigma}_{F_{1,2}(k)}$ & 0.0027 & 2.67 \\
$\sum_{k=1}^{6} \dot{\sigma}_{F_{2,3}(k)}$ & 0.0 & 0.0 \\
$\dot{\sigma}_{I}[1]$ & 642.96 & 231.84 \\
$\dot{\sigma}_{I}[2]$ & 0.142 & 207.64 \\
$\dot{\sigma}_{I}$ & 643.10 & 436.81 \\
\hline
\end{tabular}

over all relevant state variables for the globally-optimized solution are $31.32,0.0027$ and $0.0 \mathrm{~J} \mathrm{~m}^{-2} \mathrm{~d}^{-1}{ }^{\circ} \mathrm{K}^{-1}$ for fluxes $F_{0,1}, F_{1,2}$ and $F_{2,3}$, respectively. While entropy production from mixing does contribute to total entropy production, it is clear that it is small relative to the entropy of reaction terms (Table 4). 

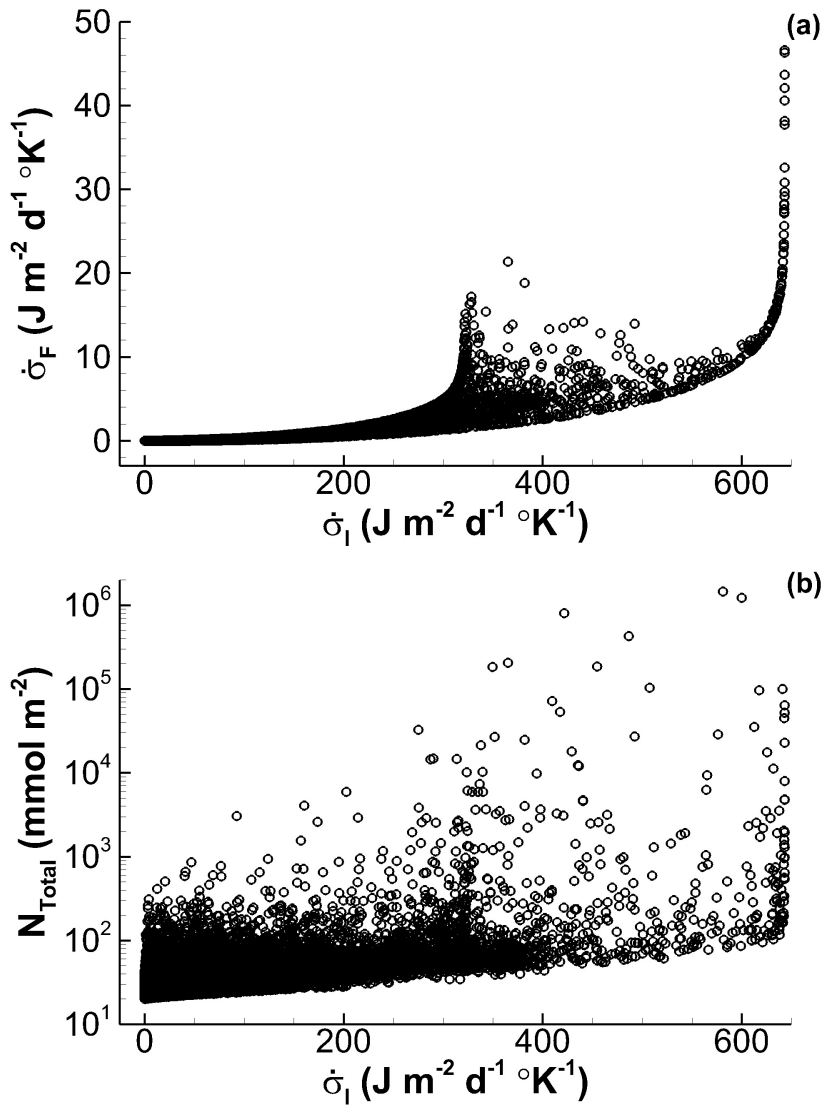

Fig. 4. Extracted results from the 100000 Monte Carlo simulations with randomly selected $\varepsilon_{i}[j]$. (a) Comparison of entropy of mixing, Eq. (13), as a function of total internal entropy production from Eq. (16). (b) Total steady state $N$ standing stock ( $\left.N_{\text {Total }}\right)$ given by Eq. (20) as a function of total internal entropy production.

Table 5. Steady state concentration $\left(\mathrm{mmol} \mathrm{m}^{-3}\right)$ of state variables at maximum internal entropy production associated with local and global solutions.

\begin{tabular}{lrrrrr}
\hline & \multicolumn{2}{c}{ Box [1] } & & \multicolumn{2}{c}{ Box [2] } \\
\cline { 2 - 3 } \cline { 5 - 6 } Variable & Global & Local & & Global & Local \\
\hline $\mathrm{CH}_{2} \mathrm{O}$ & 0.013016 & 32.085 & & $1.6025 \times 10^{-4}$ & 2.6750 \\
$\mathrm{O}_{2}$ & 190.01 & 222.09 & & 190.00 & 189.58 \\
$\mathrm{H}_{2} \mathrm{CO}_{3}$ & 2100.0 & 2067.9 & & 2100.0 & 2100.4 \\
$\mathrm{NH}_{3}$ & 1.0004 & 0.48473 & & 1.0000 & 1.0000 \\
$\mathbf{S}_{1}$ & 315.25 & 9.1628 & & 314.17 & 6.0450 \\
$\mathbf{S}_{2}$ & 57.280 & 0.69131 & & 58.360 & 0.71748 \\
\hline
\end{tabular}

If internal entropy production is maximized locally as given by Eq. (18), then the total entropy production, $\dot{\sigma}_{I}$ Eq. (16), is $436.81 \mathrm{~J} \mathrm{~m}^{-2} \mathrm{~d}^{-1}{ }^{\circ} \mathrm{K}^{-1}$, with 231.84 and $207.64 \mathrm{~J} \mathrm{~m}^{-2} \mathrm{~d}^{-1}{ }^{\circ} \mathrm{K}^{-1}$ being produced by $\dot{\sigma}_{I}[1]$ and $\dot{\sigma}_{I}[2]$, respectively (Table 4). Examination of internal en-

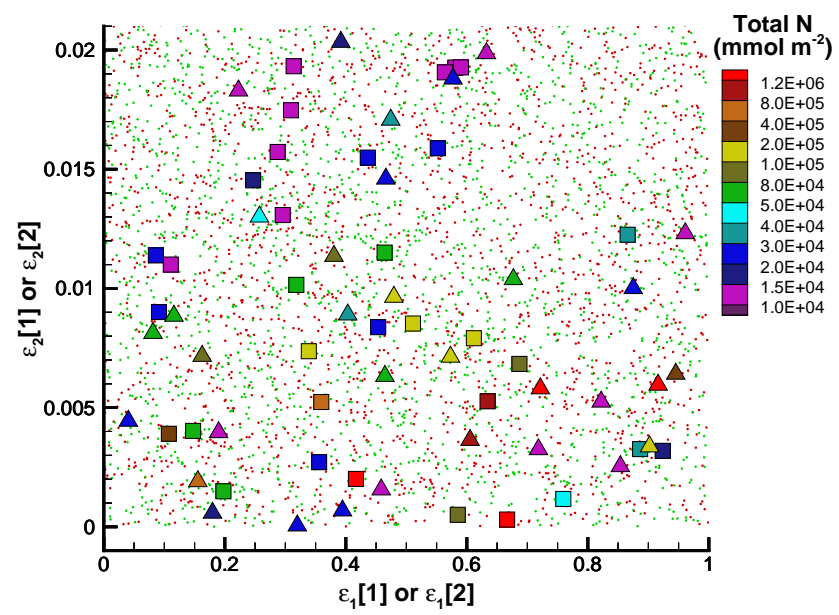

Fig. 5. Points (large triangles and squares) in 4-D $\varepsilon_{i}[j]$-space that resulted in total steady state $\mathrm{N}$ standing stock $\left(N_{\text {Total }}\right)$ greater than $10^{4} \mathrm{mmol} \mathrm{m}^{-2}$. Triangles mark locations and magnitude of $\mathrm{N}$ standing stock for $\varepsilon_{1}$ and $\varepsilon_{2}$ in box [1], while squares mark locations and $\mathrm{N}$ standing stock for $\varepsilon_{1}$ and $\varepsilon_{2}$ in box [2]. Also shown as small points are a subset of the $\varepsilon_{1}$ and $\varepsilon_{2}$ in box [1] (green) and box [2] (red) from the 100,000 Monte Carlo simulations that have $N_{\text {Total }}<10^{4} \mathrm{mmol} \mathrm{m}^{-2}$. Note, the y-axis range from 0 to 0.021 captures all points that meet the minimum $N_{\text {Total }}$ requirement of $10^{4} \mathrm{mmol} \mathrm{m}^{-2}$

tropy production in boxes [1] and [2] in the vicinity of the locally-optimized solutions (Fig. 8) illustrates that the iterative procedure used to solve Eq. (18) has indeed obtained a solution that simultaneously maximizes entropy production in both boxes, because $\dot{\sigma}_{I}[1]$ in box [1] cannot be improved with the given values of $\varepsilon_{1}$ [2] and $\varepsilon_{2}$ [2], nor can $\dot{\sigma}_{I}$ [2] in box [2] be improved given $\varepsilon_{1}$ [1] and $\varepsilon_{2}$ [1]; the solution is stable. The corresponding entropy of mixing terms for fluxes $F_{0,1}, F_{1,2}$ and $F_{2,3}$ are $3.25,2.67$ and $0.0 \mathrm{~J} \mathrm{~m}^{-2} \mathrm{~d}^{-1}{ }^{\circ} \mathrm{K}^{-1}$, respectively.

Comparing steady state solutions from the global versus the local optimizations shows that $\mathrm{CH}_{2} \mathrm{O}$ concentration in boxes [1] and [2] is near zero in the globally-optimized solution, but only partially depleted in the locally-optimize solution (Table 5). The inability to effectively oxidize $\mathrm{CH}_{2} \mathrm{O}$ in box [1] in the locally-optimized solution results from an insufficient development of biological structure ( ${ }_{1}$ and ${ }_{2}$ ), as it is evident in Fig. 4b that illustrates a lower boundary on $N_{\text {Total }}$ exists for a given entropy production rate. Biological reactions are ultimately limited by the quantity of catalyst available that in turn is limited by elemental resources. The spatial model configuration is such that state variables in box [1] control energy acquisition across boundary [0], while box [2] controls resource input across boundary [3]. Limitations in either flux will result in lower entropy production rates. In the local optimization given by Eq. (18), maximizing entropy production in box [2] ultimately results 

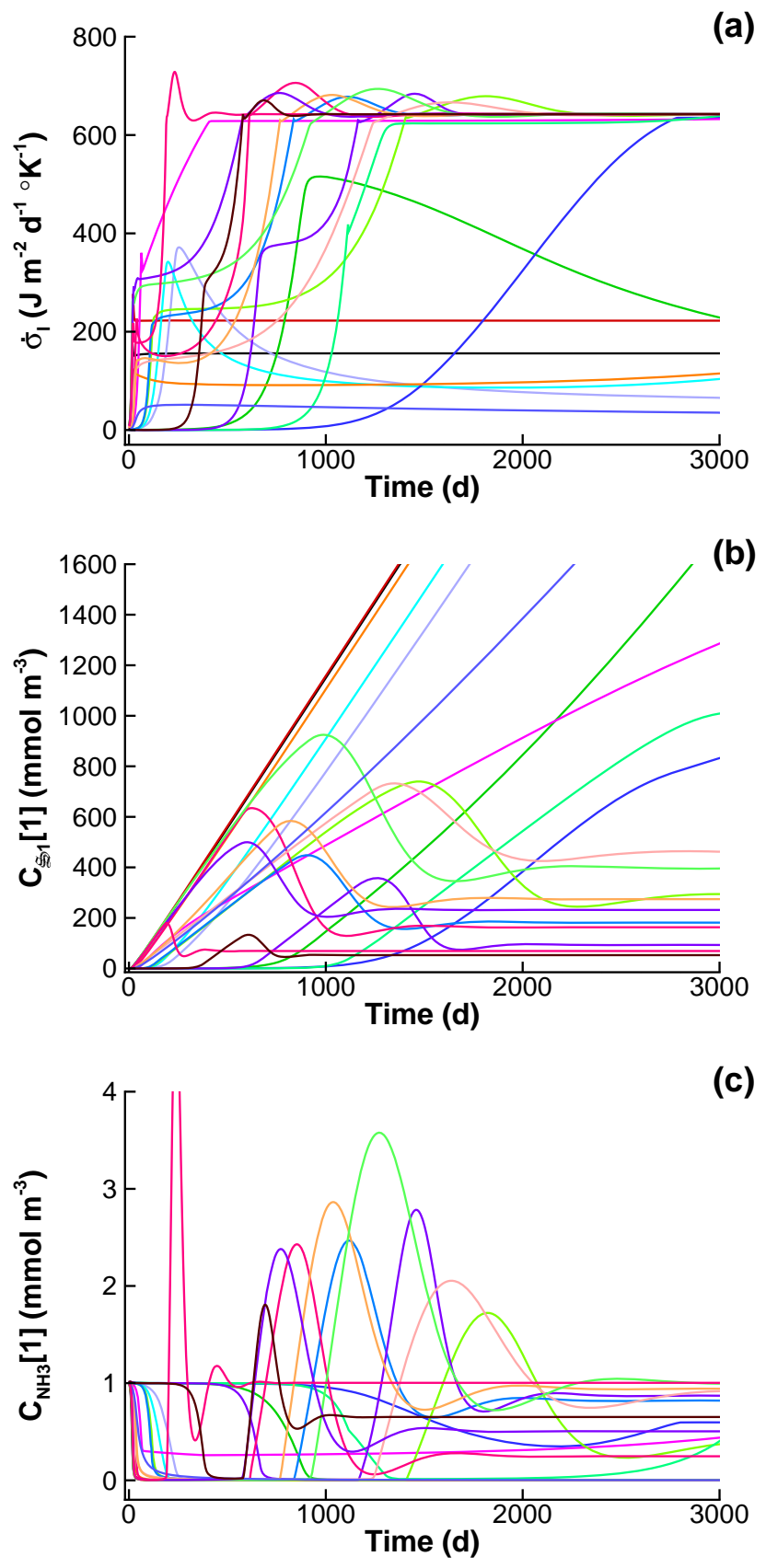

Fig. 6. Transient data for the top 20 entropy producing solutions from the 100,000 Monte Carlo simulations. (a) Total internal entropy production from both boxes [1] and [2] whoes steady state values range from 642.22 to $643.07 \mathrm{~J} \mathrm{~m}^{-2} \mathrm{~d}^{-1}{ }^{\circ} \mathrm{K}^{-1}$. (b) Concentration of biological structure in box [1], $C_{\mathcal{S}_{1}}$, and (c) $\mathrm{NH}_{3}$ over the first 3000 days of simulation. Values of $\varepsilon_{i}[j]$ for the above simulations are given in Table 3.
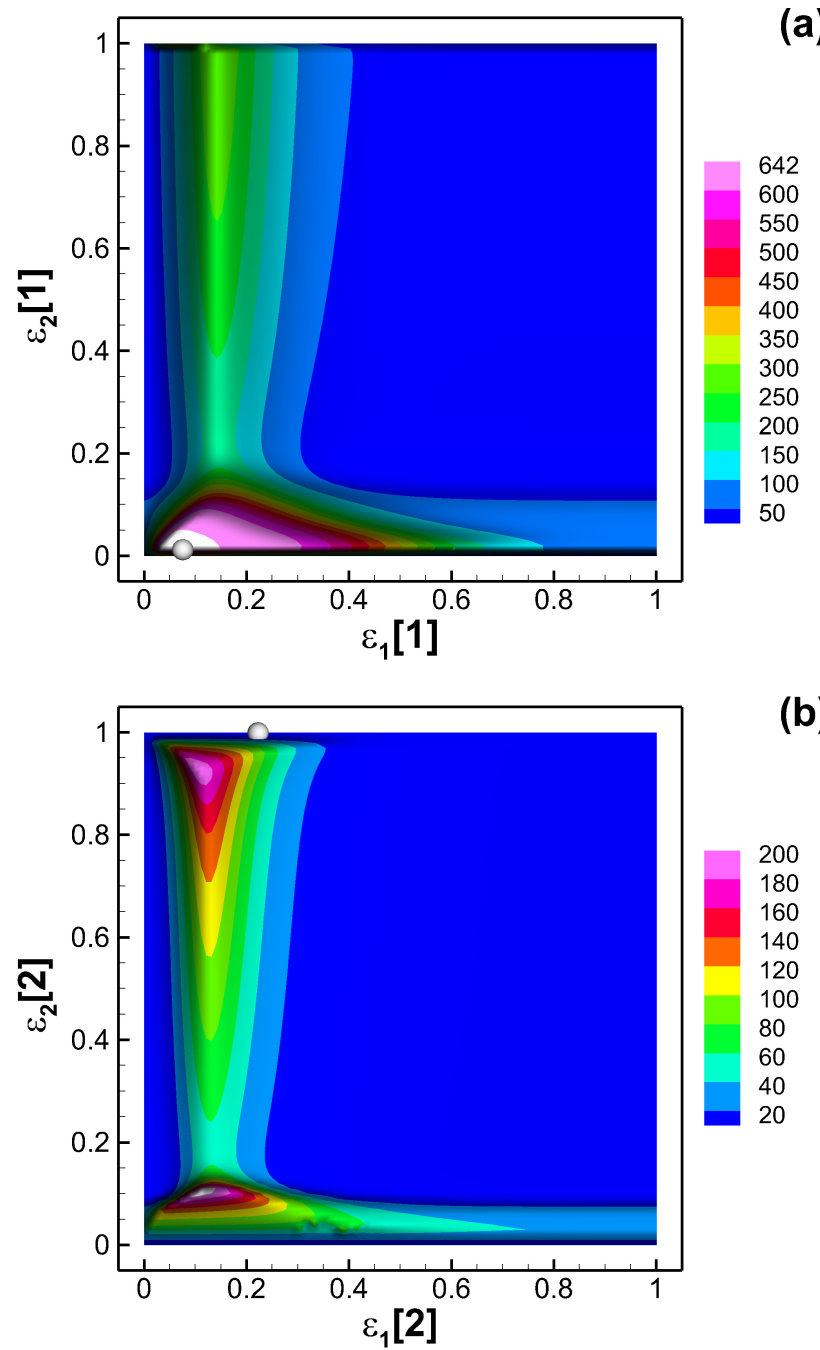

Fig. 7. Internal entropy production in (a) box [1], Eq. (14) as a function $\varepsilon_{1}$ and $\varepsilon_{2}$ in box [1] for a fixed value of $\varepsilon_{1}$ and $\varepsilon_{2}$ in box [2] of 0.2222 and 0.9998, respectively, and (b) in box [2], Eq. (15), as a function $\varepsilon_{1}$ and $\varepsilon_{2}$ in box [2] for a fixed value of $\varepsilon_{1}$ and $\varepsilon_{2}$ in box [1] of 0.0754 and 0.0123 , respecitvely. White point in (a) and (b) dentotes the position of the global MEP solution in boxes [1] and [2] based on Eq. (19) (Table 4).

in less $\mathrm{N}$ transported into the system from boundary [3]. In the globally optimize solution, net synthesis of ${ }_{1}[2]$ is critical in $\mathrm{N}$ acquisition, because when reaction (1) exceeds reaction (2) in box [2] there is a net transport of $\mathrm{NH}_{3}$ into the system that accumulates in 12 [ In the locally optimize solution, entropy production in box [2] occurs via a large loop flow between reactions (1) and (2), but this limits $\mathrm{N}$ acquisition and entropy production in box [1]. These simulations clearly demonstrate that optimizing local entropy production limits whole system resource and energy acquisition, which results in lower entropy production compared to the globally optimized solution that more effectively utilizes available resources to dissipate free energy. 


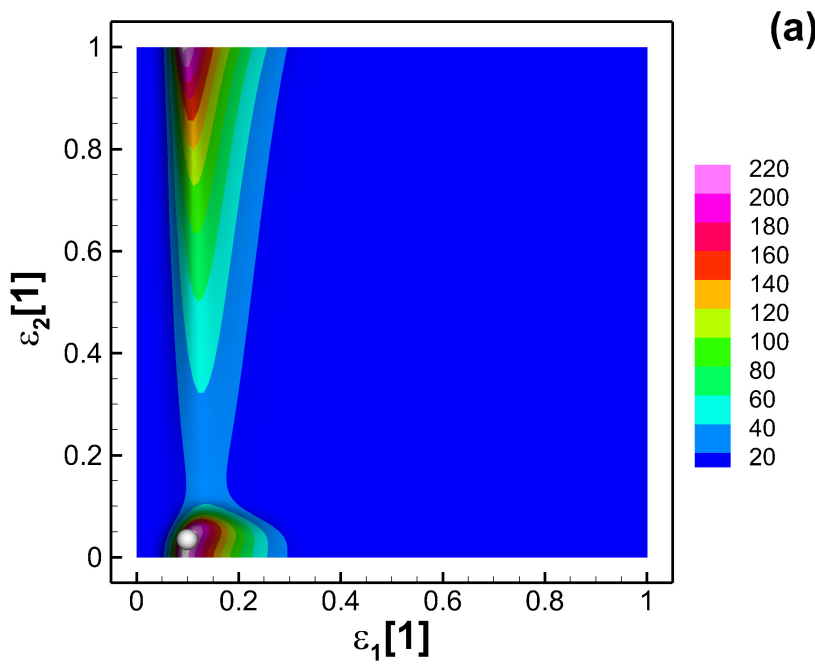

(a)

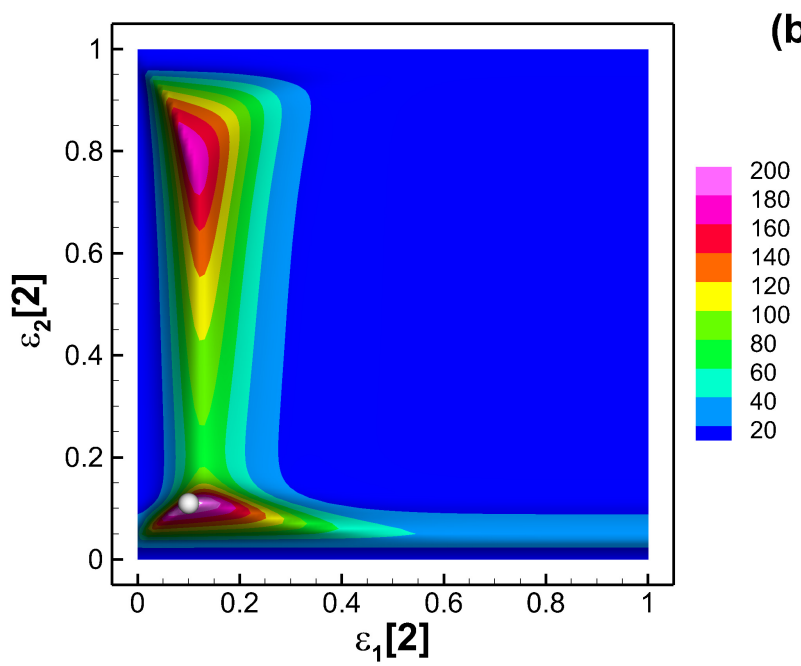

Fig. 8. Interal entropy production in (a) box [1], Eq. (14), as a function $\varepsilon_{1}$ and $\varepsilon_{2}$ in box [1] for a fixed value of $\varepsilon_{1}$ and $\varepsilon_{2}$ in box [2] of 0.0997 and 0.1100, respectively, and (b) in box [2], Eq. (15), as a function $\varepsilon_{1}$ and $\varepsilon_{2}$ in box [2] for a fixed value of $\varepsilon_{1}$ and $\varepsilon_{2}$ in box [1] of 0.0991 and 0.0352 , respecitvely. White point in (a) and (b) dentotes the position of the local MEP solution in boxes [1] and [2] based on Eq. (18) (Table 4).

We also investigated globally and locally optimized solutions with different values of the transport parameters (namely $D, \ell, h[1]$ and $h[2]$ ), but in each case the general conclusion was supported; entropy production is greater when maximized globally rather than locally. A second variation of the model was also investigated that included two additional state variables, $\mathscr{B}_{1}^{*}[j]$ and $\mathscr{B}_{2}^{*}[j]$, in each box, where the $*$ superscript indicates inactive biological structure that does not catalyze reactions (1) or (2). The rational for this model was that ${ }_{i}$ optimized in box $[j]$ would be poorly adapted to conditions in box $[k]$ and would be outcompeted, but could serve as substrate in reaction (2). In this alternate model, diffusion across boxes occurred between active and inactive variants of $\mathscr{S}_{i}$, as given by $\mathscr{S}_{1}[1] \leftrightarrow \mathscr{S}_{1}^{*}[2]$, $\mathscr{S}_{2}[1] \leftrightarrow \mathscr{S}_{2}^{*}[2], \mathscr{S}_{1}^{*}[1] \leftrightarrow \mathscr{S}_{1}[2]$ and $\mathscr{S}_{2}^{*}[1] \leftrightarrow \mathscr{S}_{2}[2]$. This modified version of the model also produced similar results, where global optimization resulted in total entropy production of $643.1 \mathrm{~J} \mathrm{~m}^{-2} \mathrm{~d}^{-1}{ }^{\circ} \mathrm{K}^{-1}$, but local optimization generated entropy at a rate of only $419.8 \mathrm{~J} \mathrm{~m}^{-2} \mathrm{~d}^{-1}{ }^{\circ} \mathrm{K}^{-1}$. Next, we examine how our approach and conclusions may be extrapolated to a more ecologically relevant context.

\section{Broader ecological context}

The model we have developed is obviously chosen to illustrate various aspects in the application of MEP in spatially explicit situations, and does not represent any natural system per say. The ideas we explore here, based on the development and results of our modeling exercise, are intended to examine the usefulness of the MEP principle for understanding biogeochemical processes. The two main questions the MEP community must address are (1) do biological systems organize towards an MEP state and (2) if so, is this knowledge useful for understanding and modeling biogeochemistry? This manuscript does not address question (1), as we implicitly assume it to be true; instead, we focus on question (2).

Ecosystem processes and the resulting biogeochemistry are often viewed from an organismal perspective, because organisms are the autonomous parts that comprise an ecosystem. Furthermore, since macroscopic ecosystem constituents appear relatively stable over timescales of human interest, it is common practice to characterize and model ecosystems with a relatively static species composition. However, the fossil record clearly shows that ecosystem communities exhibit great change over time (Gaidos et al., 2007), which is particularly evident in microbial systems whose characteristic timescales are short (Falkowski and Oliver, 2007; Fernandez et al., 2000, 1999). The MEP perspective indicates there should be many different means of attaining the same MEP state under a given set of constraints (Dewar, 2003). Consequently, ecosystem biogeochemistry is not constrained to one particular set of species, but can be attained by an infinite number of complementary species sets, with the sets being interchangeable. By complementary we mean the community must be comprised of organisms capable of energy acquisition and element recycling, so that at steady state only free energy is dissipated. The Earth's biosphere obviously operates in this mode, as there is no significant net accumulation or loss of biomass over time, but the conversion of electromagnetic radiation into longer wavelengths produces entropy. We have attempted to embody the idea of species composition fluidity in the kinetic expressions, Eqs. (4) and (5), where the choice of $\varepsilon_{i}$ defines the kinetics of the community. To implement MEP, different modeling approaches 
need to be developed that are independent of species composition, which Eq. (4) is but one example.

The MEP approach also highlights the importance of resource acquisition for the construction of biological structures needed to dissipate free energy. Different community parameterizations lead to different levels of $\mathrm{N}$ acquisition and biological structure concentrations with a minimum $S_{T}$ concentration required to achieve a given rate of entropy production (Fig. 4b). This perspective differs from the current paradigm of Liebig's Law of the Minimum, which focuses solely on elemental limitations at the organismal level. Because organism stoichiometry changes to match resource availability over evolutionary time scales (Elser et al., 2000, 2007), Liebig's law becomes a weak constraint. From the MEP perspective, resources will be extracted based on catalyst compositions that achieve the highest rate of free energy dissipation as constrained by organic chemistry. To quote Lineweaver and Egan (2008) "This represents a paradigm shift from "we eat food" to "food has produced us to eat it".

The 20 highest entropy producing solutions in the Monte Carlo simulations illustrate that very different "food web" configurations, as defined by $\varepsilon_{i}[j]$, can nevertheless dissipate free energy at statistically similar rates (Table 3). Each of these MEP solutions can be considered as meta-stable or as alternate stable states, because a perturbation of sufficient magnitude, or alteration of initial conditions, can lead the system to a different MEP basin of attraction where different ecosystem processes are exhibited for the same boundary conditions, such as occurs in shifts between macroalgae and coral reefs (Mumby, 2009), in microbial communities (Price and Morin, 2004) and in many other systems (Schröder et al., 2005). Likewise, altering system drivers or boundary conditions will change the ecosystem configuration necessary to maintain an MEP state, which would likely lead to regime shifts (Brock and Carpenter, 2010). All of the solutions in Table 3 are stable states, as they were obtained via integration of the ODEs (Appendix A) to steady state. Unlike most analyses based on a discrete selection of food web components with fixed parameter values, our approach based on Eqs. (4) and (5) selects from a continuum of possible food web configurations that could arise over long periods of evolution, but does not produce a statistically unique solution (Table 3). While we have not investigated stability aspects of the MEP solutions in this manuscript, the MEP perspective may be useful in such analyses.

The optimization criteria implicit in MEP allows parameter values to be determined for a given set of environmental conditions and drivers instead of being fit to experimental data (e.g., Table 4). This improves model robustness as parameter values can be determined for conditions where experimental data are lacking, or where model resolution is coarse compared to the underlying physics, such as in modeling global heat transport (Paltridge, 1975; Kleidon et al., 2003). The optimization approach also replaces knowledge on information content in a system. As stated in the intro- duction, genomic information allows biological systems to out-compete abiotic systems under some situations when averaged over time and/or space. However, it is not just Shannon information, but useful information (Adami et al., 2000) that is relevant; e.g., genes that allow sulfate to serve as an electron acceptor are useless if sulfate is not present in the environment. This context dependency of genomic information complicates decoding an ecosystem's metagenome. While great strides are being made at reading and decoding environmental genomic data (DeLong, 2009; Gianoulis et al., 2009), we are still far from using that information to predict ecosystem biogeochemistry (Keller, 2005; Frazier et al., 2003). By assuming all known metabolic capabilities are present in a system, MEP-based optimization can determine which pathways may be expressed and when (Vallino, 2010); furthermore, genomic information can be incorporated into the optimization as constraints when genomic surveys indicate the lack of certain metabolic capabilities. Hence, MEP theory can be used to link genomic content to free energy dissipation.

An interesting result from our MEP-based modeling exercise is that entropy production can be increased when optimized globally versus locally. However, to achieve high entropy production requires that the system organize such that certain locations within the model domain function "suboptimally", as evident in Fig. 7b. That is, free energy dissipation in box [2] is lower than possible, but this allows greater entropy production in box [1], which more than offsets the loss of entropy production in box [2]. This "altruistic behavior" is inconsistent with standard Darwinian evolution, which places optimization soley at the level of the individual; however, our results are consistent with ideas on evolution of cooperation and multilevel selection theory (Bastolla et al., 2009; Clutton-Brock, 2009; Goodnight, 1990; Hillesland and Stahl, 2010; Nowak, 2006; Traulsen and Nowak, 2006; Wilson and Wilson, 2008). For instance, bacterial colonies are large spatial structures $(\sim \mathrm{cm})$ compared to the bacteria $(\sim \mu \mathrm{m})$ that comprise them, yet it is well established that bacteria produce quorum sensing compounds that cause bacteria on the periphery of a colony to express different genes than those in the colony's center (Camilli and Bassler, 2006; Keller and Surette, 2006; Shapiro, 1998). Communication between plants via emission of volatile organic compounds has also been demonstrated to improve plant defenses over spatial scales greater than the individual (Heil and Karban, 2010). Below ground, a single fungus can attain immense size and occupy up to 1000 ha with hyphae (Ferguson et al., 2003). Given that mycorrhizae can integrate with plant roots (Maherali and Klironomos, 2007; Vandenkoornhuyse et al., 2007; Whitfield, 2007) suggests some level of below ground communication occurs across entire forests. From a physics perspective, even an individual multicellular organism represents a large spatial structure that is $10^{3}$ to $10^{6}$ times larger than the cells that comprise it, and surely those cells are spatially coordinated. Consequently, it is clear that information 
exchange over large spatial scales exists in nature, so it is conceivable that ecosystems could coordinate over space to maximize energy acquisition and dissipation.

If ecosystem information exchange occurs over large spatial scales, and if this communication facilitates increased free energy dissipation, then the domain of a model needs to be chosen judiciously. Specifically, the model domain is defined by the spatial extent of mass and information exchange, where the latter is largely achieved by chemical signaling. In certain systems, such as microbial mats (van Gemerden, 1993), it seems reasonable to model these systems as spatially connected systems, while other systems, such as the surface and deep ocean, it is uncertain to what extent, if any, they are informationally connected over space. Furthermore, it is possible that entropy production from local optimization is statistically similar to that from global optimization, so there may be little gained from spatial communication, and local optimization (e.g., Follows et al., 2007) would be sufficient to describe system dynamics. We do not know the answer to this question, as all current biogeochemical models depend solely on local conditions and are Markovian in nature; more research is needed.

\section{Conclusions}

The maximum entropy production principle (Paltridge, 1975; Dewar, 2003) proposes that nonequilibrium abiotic or biotic systems with many degrees of freedom will organize towards a state of maximum entropy production, which is synonymous with maximizing free energy dissipation for chemical systems. The usefulness of MEP theory for understanding and modeling biogeochemistry is still under debate, and numerous applied and theoretical challenges need to be address before MEP becomes a common tool for solving problems in biogeochemistry. In previous work we have demonstrate how the MEP principle can be applied to biological systems under transient conditions provided entropy production is integrated over time (Vallino, 2010). In this manuscript we have examined how biogeochemical predictions differ if entropy production is maximized locally versus globally for systems involving spatial dimensions. Biological systems explore biogeochemical reaction space over short time scales primarily via changes in community composition and gene expression; consequently, we have developed a simple kinetic expression, given by Eq. (4), to capture changes in community composition that govern biogeochemistry by using a single parameter, $\varepsilon_{i}$, that varies between 0 and 1 . Investigating MEP in a simple two-box biogeochemistry model involving two chemical reactions has revealed that globally optimized solutions generate higher entropy production rates than locally optimized solutions (Table 4), and there exists many alternate steady state solutions that produce statistically similar rates of entropy (Table 3). Results from globally optimized MEP solutions support hypotheses regarding the evolution of cooperation in biological systems and the benefit of exchanging information over space for resource acquisition to maximize dissipation of available free energy.

\section{Appendix A}

\section{Model equations and parameter values}

The complete expansion of Eq. (17) for the 6 constituents in the two boxes with associated boundaries shown in Fig. 1 are given below. For box [1] constituents we have,

$$
\begin{aligned}
\frac{d C_{\mathrm{CH}_{2} \mathrm{O}}[1]}{d t}= & \left(F_{0,1}\left(\mathrm{CH}_{2} \mathrm{O}\right)-F_{1,2}\left(\mathrm{CH}_{2} \mathrm{O}\right)\right) \\
& / h[1]-r_{1}[1] \\
\frac{d C_{\mathrm{O}_{2}}[1]}{d t}= & \left(F_{0,1}\left(\mathrm{O}_{2}\right)-F_{1,2}\left(\mathrm{O}_{2}\right)\right) / h[1] \\
- & \left(1-\varepsilon_{1}[1]\right) r_{1}[1]-\left(1-\varepsilon_{2}[1]\right) r_{2}[1] \\
\frac{d C_{\mathrm{H}_{2} \mathrm{CO}_{3}[1]}^{d t}=}{d t} & \left(F_{0,1}\left(\mathrm{H}_{2} \mathrm{CO}_{3}\right)-F_{1,2}\left(\mathrm{H}_{2} \mathrm{CO}_{3}\right)\right) / h[1] \\
+ & \left(1-\varepsilon_{1}[1]\right) r_{1}[1]+\left(1-\varepsilon_{2}[1]\right) r_{2}[1]
\end{aligned}
$$

$$
\begin{aligned}
\frac{d C_{\mathrm{NH}_{3}}[1]}{d t} & =-F_{1,2}\left(\mathrm{NH}_{3}\right) / h[1]-\rho \varepsilon_{1}[1] r_{1}[1] \\
& +\rho\left(1-\varepsilon_{2}[1]\right) r_{2}[1]
\end{aligned}
$$

$\frac{d C_{\mathscr{S}_{1}}[1]}{d t}=-F_{1,2}\left(\dot{g}_{1}\right) / h[1]+\varepsilon_{1}[1] r_{1}[1]-\delta_{1}[1] r_{2}[1]$

$\frac{d C_{\mathscr{g}_{2}}[1]}{d t}=-F_{1,2}\left(\mathscr{g}_{2}\right) / h[1]+\left(\varepsilon_{2}[1]-\delta_{2}[1]\right) r_{2}[1]$

For box [2] constituents, the equations are,

$$
\begin{aligned}
\frac{d C_{\mathrm{CH}_{2} \mathrm{O}}[2]}{d t}=F_{1,2}\left(\mathrm{CH}_{2} \mathrm{O}\right) / h[2]-r_{1}[2] \\
\begin{aligned}
\frac{d C_{\mathrm{O}_{2}}[2]}{d t} & =F_{1,2}\left(\mathrm{O}_{2}\right) / h[2]-\left(1-\varepsilon_{1}[2]\right) r_{1}[2] \\
& -\left(1-\varepsilon_{2}[2]\right) r_{2}[2]
\end{aligned}
\end{aligned}
$$

$$
\begin{aligned}
\frac{d C_{\mathrm{H}_{2} \mathrm{CO}_{3}[2]}[t}{d t} & =F_{1,2}\left(\mathrm{H}_{2} \mathrm{CO}_{3}\right) / h[2] \\
& +\left(1-\varepsilon_{1}[2]\right) r_{1}[2]+\left(1-\varepsilon_{2}[2]\right) r_{2}[2]
\end{aligned}
$$

$$
\begin{aligned}
\frac{d C_{\mathrm{NH}_{3}}[2]}{d t}= & \left(F_{1,2}\left(\mathrm{NH}_{3}\right)-F_{2,3}\left(\mathrm{NH}_{3}\right)\right) / h[2] \\
& -\rho \varepsilon_{1}[2] r_{1}[2]+\rho\left(1-\varepsilon_{2}[2]\right) r_{2}[2]
\end{aligned}
$$

$$
\frac{d C_{\mathcal{S}_{1}}[2]}{d t}=F_{1,2}\left(\dot{S}_{1}\right) / h[2]+\varepsilon_{1}[2] r_{1}[2]-\delta_{1}[2] r_{2}[2]
$$




$$
\frac{d C_{\mathcal{S}_{2}}[2]}{d t}=F_{1,2}\left(\mathcal{G}_{2}\right) / h[2]+\left(\varepsilon_{2}[2]-\delta_{2}[2]\right) r_{2}[2]
$$

Fluxes, $F_{i, j}(k)$, where $\beta_{i, j}(k)$ in Eq. (12) equals zero have been removed from the above expressions. Parameter values, initial conditions plus boundary conditions used for all simulations are given in Tables 1 and 2, respectively.

Acknowledgements. I thank Axel Kleidon for organizing the 2010 workshop on Non-Equilibrium Thermodynamics and MEP in the Earth system that lead to this manuscript. The work presented here was funded by the NSF Advancing Theory in Biology Program (NSF EF-0928742), the NSF PIE-LTER program (NSF OCE0423565 ) as well as from NSF CBET-0756562 and OCE-0852263.

Edited by: V. Lucarin

\section{References}

Adami, C.: Sequence complexity in Darwinian evolution, Complexity, 8(2), 49-56, doi:10.1002/cplx.10071, 2002.

Adami, C., Ofria, C., and Collier, T. C.: Evolution of biological complexity, P. Natl. Acad. Sci. USA, 97(9), 4463-4468, 2000.

Alberty, R. A.: Thermodynamics of biochemical reactions, Hoboken, NJ, Wiley \& Sons, pp. 397, 2003.

Alberty, R. A.: Biochemical thermodynamics: Applications of Mathematica, Hoboken, NJ, Wiley \& Sons, pp. 464, 2006.

Aoki, I.: Entropy law in aquatic communities and the general entropy principle for the development of living systems, Ecol. Modelling, 215(1-3), 89-92, doi:10.1016/j.ecolmodel.2008.02.011, 2008.

Bailey, J. E.: Biochemical engineering fundamentals, New York, NY, McGraw-Hill, pp. 753, 1977.

Bain, R. S.: Solution of nonlinear algebraic equation systems; and, Single and multiresponse nonlinear parameter estimation problems, Ph.D. Thesis/Dissertation, University of Wisconsin Madison, 1993.

Bastolla, U., Fortuna, M. A., Pascual-Garcia, A., Ferrera, A., Luque, B., and Bascompte, J.: The architecture of mutualistic networks minimizes competition and increases biodiversity, Nature, 458(7241), 1018-1020, doi:10.1038/nature07950, 2009.

Battley, E. H.: An empirical method for estimating the entropy of formation and the absolute entropy of dried microbial biomass for use in studies on the thermodynamics of microbial growth, Thermochim. Acta, 326(1-2), 7-15, 1999a.

Battley, E. H.: On entropy and absorbed thermal energy in biomass; a biologist's perspective, Thermochim. Acta, 331,(1), 1-12, 1999b.

Battley, E. H.: Absorbed heat and heat of formation of dried microbial biomass: Studies on the thermodynamics of microbial growth, J. Therm. Anal. Calorim., 74(3), 709-721, doi:10.1023/B:JTAN.0000011003.43875.0d, 2003.

Bejan, A.: Constructal theory of pattern formation, Hydrol. Earth Syst. Sci., 11, 753-768, doi:10.5194/hess-11-753-2007, 2007.

Boudart, M.: Consistency between kinetics and thermodynamics, J. Phys. Chem., 80(26), 2869-2870, 1976.

Brock, W. A. and Carpenter, S. R.: Interacting regime shifts in ecosystems: implication for early warnings, Ecol. Monogr., 80(3), 353-367, 2010.
Brugnano, L. and Magherini, C.: The BiM code for the numerical solution of ODEs, J. Comput. Appl. Math., 164-165, 145-158, doi:10.1016/j.cam.2003.09.004, 2004.

Camilli, A. and Bassler, B. L.: Bacterial Small-Molecule Signaling Pathways, Science, 311(5764), 1113-1116, 2006.

Carlson, C. A., Bates, N. R., Ducklow, H. W., and Hansell, D. A.: Estimation of bacterial respiration and growth efficiency in the Ross Sea, Antarctica, Aquat. Microb. Ecol., 19(3), 229-244, doi:10.3354/ame019229, 1999.

Clutton-Brock, T.: Cooperation between non-kin in animal societies, Nature, 462(7269), 51-57, doi:10.1038/nature08366, 2009.

Del Giorgio, P. A. and Cole, J. J.: Bacterial growth efficiency in natural aquatic systems, Annu. Rev. Ecol. Syst., 29, 503-541, 1998.

DeLong, E. F.: The microbial ocean from genomes to biomes, Nature, 459(7244), 200-206, doi:10.1038/nature08059, 2009.

Dewar, R. C.: Information theory explanation of the fluctuation theorem, maximum entropy production and self-organized criticality in non-equilibrium stationary states, J. Phys. A-Math. Gen., 36, 631-641, 2003.

Dewar, R. C.: Maximum entropy production and the fluctuation theorem, J. Phys. A-Math. Gen., 38(21), L371-L381, doi:10.1088/0305-4470/38/21/L01, 2005.

Dewar, R. C.: Maximum Entropy Production as an Inference Algorithm that Translates Physical Assumptions into Macroscopic Predictions: Don't Shoot the Messenger, Entropy, 11(4), 931944, doi:10.3390/e11040931, 2009.

Dyke, J. and Kleidon, A.: The Maximum Entropy Production Principle: Its Theoretical Foundations and Applications to the Earth System, Entropy, 12(3), 613-630, 2010.

Edwards, A. M. and Yool, A.: The role of higher predation in plankton population models, J. Plankton Res., 22(6), 1085-1112, doi:10.1093/plankt/22.6.1085, 2000.

Elser, J. J., Sterner, R. W., Gorokhova, E., Fagan, W. F., Markow, T. A., Cotner, J. B., Harrison, J. F., Hobbie, J. E., Odell, G. M., and Weider, L. W.: Biological stoichiometry from genes to ecosystems, Ecol. Lett., 3(6), 540-550, 2000.

Elser, J. J., Bracken, M. E. S., Cleland, E. E., Gruner, D. S., Harpole, W. S., Hillebrand, H., Ngai, J. T., Seabloom, E. W., Shurin, J. B., and Smith, J. E.: Global analysis of nitrogen and phosphorus limitation of primary producers in freshwater, marine and terrestrial ecosystems, Ecol. Lett., 10(12), 1135-1142, doi:10.1111/j.14610248.2007.01113.x, 2007.

Erwin, D. H.: Macroevolution of ecosystem engineering, niche construction and diversity, Trends Ecol. Evol., 23(6), 304-310, doi:10.1016/j.tree.2008.01.013, 2008.

Eu, B. C.: Kinetic theory and irreversible thermodynamics, Montreal, John Wiley \& Sons Canada, Ltd., pp. 752, 1992.

Falkowski, P. G. and Oliver, M. J.: Mix and match: how climate selects phytoplankton, Nat. Rev. Micro., 5(10), 813-819, doi:10.1038/nrmicro1751, 2007.

Falkowski, P. G., Fenchel, T., and DeLong, E. F.: The Microbial Engines That Drive Earth's Biogeochemical Cycles, Science, 320(5879), 1034-1039, doi:10.1126/science.1153213, 2008.

Fath, B. D., Patten, B. C., and Choi, J. S.: Complementarity of Ecological Goal Functions, J. Theor. Biol., 208(4), 493-506, 2001.

Ferenci, T.: "Growth of bacterial cultures" 50 years on: towards an uncertainty principle instead of constants in bacterial growth 
kinetics, Res. Microbiol., 150(7), 431-438, doi:10.1016/S09232508(99)00114-X, 1999.

Ferguson, B. A., Dreisbach, T. A., Parks, C. G., Filip, G. M., and Schmitt, C. L.: Coarse-scale population structure of pathogenic Armillaria species in a mixed-conifer forest in the Blue Mountains of northeast Oregon, Can. J. Forest Res., 33(4), 612-623, doi:10.1139/X02-165, 2003.

Fernandez, A., Huang, S., Seston, S., Xing, J., Hickey, R., Criddle, C., and Tiedje, J.: How Stable Is Stable? Function versus Community Composition, Appl. Environ. Microb., 65(8), 3697-3704, 1999.

Fernandez, A. S., Hashsham, S. A., Dollhopf, S. L., Raskin, L., Glagoleva, O., Dazzo, F. B., Hickey, R. F., Criddle, C. S., and Tiedje, J. M.: Flexible community structure correlates with stable community function in methanogenic bioreactor communities perturbed by glucose, Appl. Microbiol. Biotechnol., 66(9), 4058-4067, 2000.

Follows, M. J., Dutkiewicz, S., Grant, S., and Chisholm, S. W.: Emergent Biogeography of Microbial Communities in a Model Ocean, Science, 315(5820), 1843-1846, doi:10.1126/science.1138544, 2007.

Frazier, M. E., Johnson, G. M., Thomassen, D. G., Oliver, C. E., and Patrinos, A.: Realizing the Potential of the Genome Revolution: The Genomes to Life Program, Science, 300(5617), 290-293, 2003

Gaidos, E., Dubuc, T., Dunford, M., McAndrew, P., PadillaGamino, J., Studer, B., Weersing, K., and Stanley, S.: The Precambrian emergence of animal life: a geobiological perspective, Geobiology, 5(4), 351-373, doi:10.1111/j.14724669.2007.00125.x, 2007.

Gianoulis, T. A., Raes, J., Patel, P. V., Bjornson, R., Korbel, J. O., Letunic, I., Yamada, T., Paccanaro, A., Jensen, L. J., Snyder, M., Bork, P., and Gerstein, M. B.: Quantifying environmental adaptation of metabolic pathways in metagenomics, PNAS, 106(5), 1374-1379, doi:10.1073/pnas.0808022106, 2009.

Goodnight, C. J.: Experimental studies of community evolution II: The ecological basis of the response to community selection, Evolution, 44(6), 1625-1636, 1990

He, J., Watson, L. T., and Sosonkina, M.: Algorithm 897: VTDIRECT95: Serial and Parallel Codes for the Global Optimization Algorithm DIRECT, Acm Transactions on Mathematical Software, 36(3(17)), 1-24, doi:10.1145/1527286.1527291, 2009.

Heil, M. and Karban, R.: Explaining evolution of plant communication by airborne signals, Trends Ecol. Evol., 25(3), 137-144, doi:10.1016/j.tree.2009.09.010, 2010.

Hillesland, K. L. and Stahl, D. A.: Rapid evolution of stability and productivity at the origin of a microbial mutualism, PNAS, 107(5), 2124-2129, doi:10.1073/pnas.0908456107, 2010.

Holling, C. S.: The functional response of predators to prey density and its role in mimicry and population regulation, Mem. Entom. Soc. Can., 45, 1-60, 1965.

Ianson, D. and Allen, S. E.: A two-dimensional nitrogen and carbon flux model in a coastal upwelling region, Global Biogeochem. Cy., 16(1), 1011, doi:10.1029/2001GB001451, 2002.

Jaynes, E. T.: Probability theory: The logic of science, Cambridge, Cambridge University Press, 758 pp., 2003.

Jin, Q. and Bethke, C. M.: A New Rate Law Describing Microbial Respiration, Appl. Environ. Microb., 69(4), 2340-2348, 2003.

Johnson, H. A.: Information Theory in Biology af- ter 18 Years, Science, 168(3939), 1545-1550, doi:10.1126/science.168.3939.1545, 1970.

Jones, C. G., Lawton, J. H., and Shachak, M.: Organisms as Ecosystem Engineers, Oikos, 69(3), 373-386, 1994.

Jones, D. R., Perttunen, C. D., and Stuckman, B. E.: Lipschitzian optimization without the Lipschitz constant, J. Optimiz. Theory App., 79(1), 157-181, 1993.

Jorgensen, S. E.: Review and comparison of goal functions in system ecology, Vie Milieu, 44(1), 11-20, 1994.

Jorgensen, S. E., Patten, B. C., and Straskraba, M.: Ecosystems emerging: 4. growth, Ecol. Modelling, 126(2-3), 249-284., 2000.

Kearfott, R. B.: Algorithm 763: Interval_Arithmetic: A Fortran 90 Module for An Interval Data Type, Acm T. Math. Software, 22(4), 385-392, 1996.

Kearfott, R. B. and Novoa, M.: Algorithm 681: INTBIS, A Portable Interval Newton Bisection Package, Acm T. Math. Software, 16(2), 152-157, 1990.

Keller, E. F.: The century beyond the gene, J. Bioscience, 30(1) 3-10, 2005.

Keller, L. and Surette, M. G.: Communication in bacteria: an ecological and evolutionary perspective, Nat. Rev. Micro., 4(4), 249-258, doi:10.1038/nrmicro1383, 2006.

Kleidon, A., Fraedrich, K., Kunz, T., and Lunkeit, F.: The atmospheric circulation and states of maximum entropy production, Geophys. Res. Lett., 30(23), 1-4, doi:10.1029/2003GL018363, 2003.

Kleidon, A. and Lorenz, R. D.: Non-equilibrium thermodynamics and the production of entropy, Springer-Verlag, Berlin, $260 \mathrm{pp}$., 2005a.

Kleidon, A. and Lorenz, R.: Entropy production by earth system processes, in: Non-equilibrium thermodynamics and the production of entropy: life, earth and beyond, 1-20, edited by: Kleidon, A. and Lorenz, R. D., Berlin, Springer-Verlag, 2005b.

Kondepudi, D. and Prigogine, I.: Modern thermodynamics: From heat engines to dissipative structures, New York, Wiley \& Sons, 486 pp., 1998.

Lendenmann, U. and Egli, T.: Kinetic models for the growth of Escherichia coli with mixtures of sugars under carbonlimited conditions, Biotechnol. Bioeng., 59(1) 99-107, doi:10.1002/(SICI)1097-0290(19980705)59:1<99::AIDBIT13>3.0.CO;2-Y, 1998.

Lineweaver, C. H. and Egan, C. A.: Life, gravity and the second law of thermodynamics, Phys. Life Rev., 5(4), 225-242, doi:10.1016/j.plrev.2008.08.002, 2008.

Lorenz, R. D., Lunine, J. I., and Withers, P. G.: Titan, Mars and Earth : Entropy production by latitudinal heat transport, Geophys. Res. Lett., 28(3), 415-418, 2001.

Lorenz, R.: COMPUTATIONAL MATHEMATICS: Full Steam Ahead-Probably, Science, 299(5608), 837-838, 2003.

Lotka, A. J.: Contribution to the Energetics of Evolution, PNAS, $8(6), 147-151,1922$.

Maherali, H. and Klironomos, J. N.: Influence of Phylogeny on Fungal Community Assembly and Ecosystem Functioning, Science, 316(5832), 1746-1748, doi:10.1126/science.1143082, 2007.

Margalef, R.: Perspectives in ecological theory, Chicago, University of Chicago Press, 112 pp., 1968.

Meysman, F. J. R. and Bruers, S.: A thermodynamic perspec- 
tive on food webs: Quantifying entropy production within detrital-based ecosystems, J. Theor. Biol., 249(1), 124-139, doi:10.1016/j.jtbi.2007.07.015, 2007.

Monod, J.: The growth of bacterial cultures, Annu. Rev. Microbiol., 3, 371-394, 1949.

Morowitz, H. J.: Some order-disorder considerations in living systems, Bull. Math. Biol., 17(2), 81-86, doi:10.1007/BF02477985, 1955.

Morowitz, H. J.: Energy flow in biology: biological organization as a problem in thermal physics, New York, Academic Press, 179 pp., 1968.

Morrison, P.: A Thermodynamic Characterization of SelfReproduction, Rev. Mod. Phys., 36(2), 517, 1964.

Mumby, P. J.: Phase shifts and the stability of macroalgal communities on Caribbean coral reefs, Coral Reefs, 28(3), 761-773, 2009.

Niven, R. K.: Steady state of a dissipative flow-controlled system and the maximum entropy production principle, Phys. Rev. E (Statistical, Nonlinear, and Soft Matter Physics), 80(2), 021113021115, doi:10.1103/PhysRevE.80.021113, 2009.

Nowak, M. A.: Five Rules for the Evolution of Cooperation, Science, 314(5805), 1560-1563, doi:10.1126/science.1133755, 2006.

Odum, H. T. and Pinkerton, R. C.: Time's speed regulator: the optimum efficiency for maximum power output in physical and biological systems, Am. Sci., 43, 321-343, 1955.

Paltridge, G. W.: Global dynamics and climate-a system of minimum entropy exchange, Q. J. Roy. Meteorol. Soc., 104, 927-945, 1975.

Pianka, E. R.: R-Selection and K-Selection, Amer. Nat., 104(940) 592-597, 1970.

Price, J. E. and Morin, P. J.: Colonization history determines alternate community states in a food web of intraguild predators, Ecology, 85(4) 1017-1028, doi:10.1890/03-0157, 2004.

Prigogine, I. and Nicolis, G.: Biological order, structure and instabilities, Q. Rev. Biophys., 4, 107-148, 1971.

Schneider, E. D. and Kay, J. J.: Complexity and thermodynamics: towards a new ecology, Futures, 26(6), 626-647, 1994.

Schröder, A., Persson, L., and De Roos, A. M.: Direct experimental evidence for alternative stable states: a review, Oikos, 110(1), 3-19, doi:10.1111/j.0030-1299.2005.13962.x, 2005.
Schrödinger, E.: What is life?, Cambridge, UK, Cambridge University Press, 1944.

Shannon, C. E.: A mathematical theory of communication, AT\&T Tech. J., 27, 379-423, 623-656, 1948.

Shapiro, J. A.: Thinking about bacterial populations as multicellular organisms, Annu. Rev. Microbiol., 52, 81-104, 1998.

Smith, S. L., Yamanaka, Y., Pahlow, M., and Oschlies, A.: Optimal uptake kinetics: physiological acclimation explains the pattern of nitrate uptake by phytoplankton in the ocean, Mar. Ecol. Prog. Ser., 384, 1-12, doi:10.3354/meps08022, 2009.

Toussaint, O. and Schneider, E. D.: The thermodynamics and evolution of complexity in biological systems, Comp. Biochem. Physiol. A, 120(1), 3-9, 1998.

Traulsen, A. and Nowak, M. A.: Evolution of cooperation by multilevel selection, PNAS, 103(29), 10952-10955, doi:10.1073/pnas.0602530103, 2006.

Ulanowicz, R. E. and Platt, T.: Ecosystem theory for biological oceanography, Can. Bull. Fish. Aquat. Sci., 213, Ottawa, 260 pp., 1985.

Vallino, J. J.: Ecosystem biogeochemistry considered as a distributed metabolic network ordered by maximum entropy production, Phil. Trans. R. Soc. B, 365(1545), 1417-1427, doi:10.1098/rstb.2009.0272, 2010.

van Gemerden, H.: Microbial mats: A joint venture, Mar. Geol., 113(1-2) 3-25, doi:10.1016/0025-3227(93)90146-M, 1993.

Vandenkoornhuyse, P., Mahe, S., Ineson, P., Staddon, P., Ostle, N., Cliquet, J. B., Francez, A. J., Fitter, A. H., and Young, J. P.: Active root-inhabiting microbes identified by rapid incorporation of plant-derived carbon into RNA, PNAS, 104(43), 16970-16975, doi:10.1073/pnas.0705902104, 2007.

Weber, B. H., Depew, D. J., and Smith, J. D.: Entropy, information, and evolution: New perspective on physical and biological evolution, MIT Press, Cambridge, MA, pp. 390, 1988.

West, G., Brown, J. H., and Enquist, B. J.: A General Model for the Origin of Allometric Scaling Laws in Biology, Science, 276(5309), 122-126, doi:10.1126/science.276.5309.122, 1997.

Whitfield, J.: Fungal roles in soil ecology: Underground networking, Nature, 449(7159), 136-138, doi:10.1038/449136a, 2007.

Wilson, D. S. and Wilson, E. O.: Evolution for the Good of the Group, Am. Sci., 96(5), 380-389, doi:10.1511/2008.74.1, 2008. 